\title{
Standard Beta-Particle and
}

Monoenergetic Electron Sources for the Calibration of

Beta-Radiation Protection Instrumentation

Jointly Sponsored by the U.S. Nuclear Regulatory Commission and the U.S. Department of Commerce

Prepared by M. Ehrlich, J. S. Pruitt, C. G. Soares

Contributions made also by C. E. Dick, H. T. Heaton, II, and R. B. Schwartz

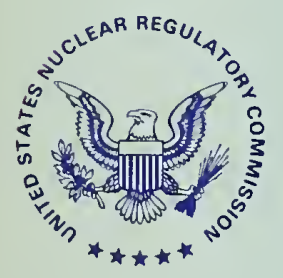

U.S. Nuclear Regulatory Commission

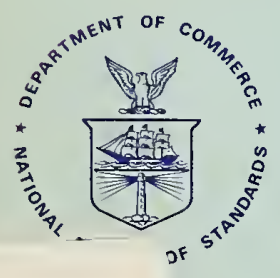

U. S. Department of Commerce

National Bureau of Standards 
This report was prepared as an account of work sponsored by an agency of the United States Government. Neither the United States Government nor any agency thereof, or any of their employees, makes any warranty, expressed or implied, or assumes any legal liability of responsibility for any third party's use, or the results of such use, of any information, apparatus, product or process disclosed in this report, or represents that its use by such third party would not infringe privately owned rights.

\section{NOTICE}

Availability of Reference Materials Cited in NRC Publications

Most documents cited in NRC publications will be available from one of the following sources:

1. The NRC Public Document Room, 1717 H Street, N.W. Washington, DC 20555

2. The Superintendent of Documents, U.S. Government Printing Office, Post Office Box 37082 , Washington, DC 20013-7082

3. The National Technıcal Information Service, Springfield, VA 22161

Although the listing that follows represents the majority of documents cited in NRC publications, it is not intended to be exhaustive.

Referenced documents available for inspection and copying for a fee from the NRC Public Document Room include NRC correspondence and internal NRC memoranda; NRC Office of Inspection and Enforcement bulletins, circulars, information notices, inspection and investigation notices; Licensee Event Reports; vendor reports and correspondence; Commission papers; and applicant and licensee documents and correspondence.

The following documents in the NUREG series are available for purchase from the NRC/GPO Sales Program: formal NRC staff and contractor reports, NRC-sponsored conference proceedings, and NRC booklets and brochures. Also available are Regulatory Guides, NRC regulations in the Code of Federal Regulations, and Nuclear Regulatory Commission Issuances.

Documents available from the National Technical Information Service include NUREG series reports and technical reports prepared by other federal agencies and reports prepared by the Atomic Energy Commission, forerunner agency to the Nuclear Regulatory Commission.

Documents available from public and special technical libraries include all open literature items, such as books, journal and periodical articles, and transactions. Federal Register notices, federal and state legislation, and congressional reports can usually be obtained from these libraries.

Documents such as theses, dissertations, foreign reports and translations, and non-NRC conference proceedings are available for purchase from the organization sponsoring the publication cited.

Single copies of NRC draft reports are available free, to the extent of supply, upon written request to the Division of Technical Information and Document Control, U.S. Nuclear Regulatory Commission, Washington, DC 20555.

Copies of industry codes and standards used in a substantive manner in the NRC regulatory process are maintained at the NRC Library, 7920 Norfolk Avenue, Bethesda, Maryland, and are available there for reference use by the public. Codes and standards are usually copyrighted and may be purchased from the originating organization or, if they are American National Standards, from the American National Standards Institute, 1430 Broadway, New York, NY 10018. 
Standard Beta-Particle and

NATIONAL BUREAU OF STAYDARDS

Monoenergetic Electron Sources

for the Calibration of

Beta-Radiation Protection

Instrumentation

Jointly Sponsored by the U.S. Nuclear Regulatory Commission and the U.S. Department of Commerce

Manuscript Completed: May 1985

Date Published: August 1985

Prepared by

M. Ehrlich, J. S. Pruitt, C. G. Soares

Contributions made also by C. E. Dick, H. T. Heaton, II, and R. B. Schwartz

U.S. Nuclear Regulatory Commission

Washington, D.C. 20555

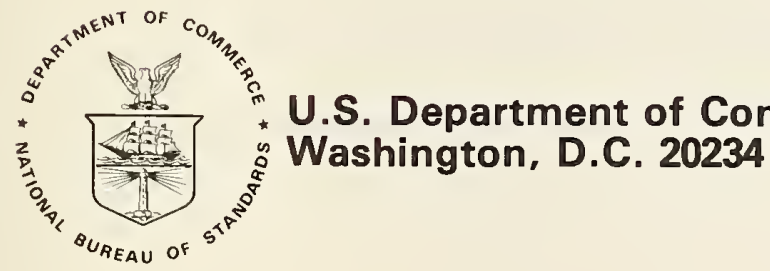

Prepared for

Division of Radiation Programs and Earth Sciences

Office of Nuclear Regulatory Research

U.S. Nuclear Regulatory Commission

Washington, D.C. 20555

NRC FIN B8271

and

Center for Radiation Research

National Bureau of Standards

U. S. Department of Commerce

Gaithersburg, MD 20899 



\section{ABSTRACT}

In a project funded jointly by the National Bureau of Standards (NBS) and the Nuclear Regulatory Commission (NRC), NBS has developed a calibration facility for beta-particle instruments and sources used in radiationprotection dosimetry. The facility consists of beta-particle and nearly monoenergetic electron beams characterized in terms of absorbed-dose rates to plastic and in terms of beta-particle spectra. A second phase of the project was concerned with establishing secondary calibration laboratories for radiation-protection instruments.

This final report includes a detailed discussion of (1) the determination of absorbed-dose rates to plastic for each beta-particle and nearly monoenergetic electron beam, dose-rate dependence on altitude above sea level, and an estimate of the overall uncertainties in dose-rate measurements; (2) betaparticle and nearly monoenergetic electron spectra and their dependence on source configuration; and (3) degree of achievable uniformity of beam cross sections. Included also is a review of the results of a first attempt to predict instrument response to realistic beta-particle environments from their response to monoenergetic electrons and knowledge of the approximate betaparticle spectra. Attached to the report are proposed guidelines for establishing secondary calibration laboratories for radiation-protection instruments. 



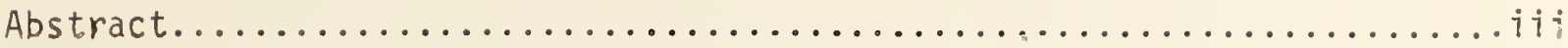

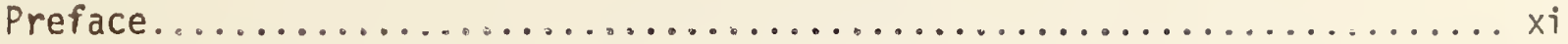

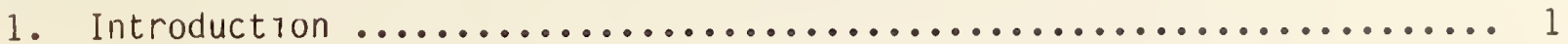

2. The NBS Beta-Particle Calibration Facility.................... 3

2.1 Measurement of Absorbed-Dose Rates...................... 3

2.1.1 Absorbed-dose rates to air......................... 3

2.1.2 Uncertainty in the Determination of Absorbed-Dose Rate

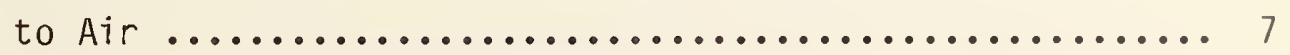

2.1.3 Determination of Absorbed-Dose Rate to Plastic as a Function of Depth in Plastic ..................... 15

2.2 Beta-Particle Spectral Composition at the Reference Point ..... 18

2.3 Comparison of Different Types of ${ }^{90} \mathrm{Sr}+{ }^{90} \mathrm{Y}$ Sources ........... 27

3. The NBS Close-to-Monoenergetic Electron Calibration Facility ....... 28



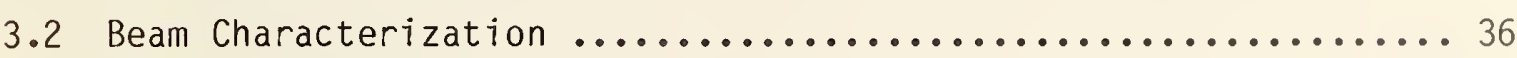

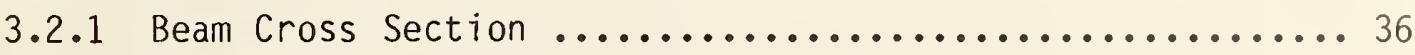

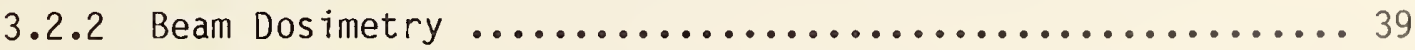

3.2.3 Spectral Composition of the Electron Beam at the

Reference Point ................................. 39

4. Prediction of Instrument Response to Beta Particles from Response to

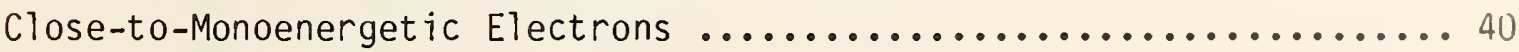

5. Guidelines for Establishing Secondary Calibration Laboratories for Radiation-Protection Sources and Instruments ..................49

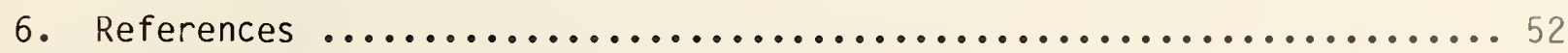
Appendix 1 Beta-Ray Source Calibration Procedure and Error Analysis..... 53 Appendix 2 Proposed Guidelines for Establishing a Secondary Calibration Laboratory for Beta-Particle Source Standardization and Calibration of Beta-Particle Protection Instruments ......... 57 Appendix 3 Proposed Guidelines for Establishing a Secondary Calibration Laboratory for Neutron-Protection Instruments ............6 65 Appendix 4 Proposed Procedure for Carrying out Measurement-Assurance Studies for a Secondary Calibration Laboratory ............ 72 

LIST OF FIGURES

Page

Figure 1 Beta-Particle Calibration Facility.................. 4

Figure 2 Theoretical Beta-Particle Spectra for the Radionuclides

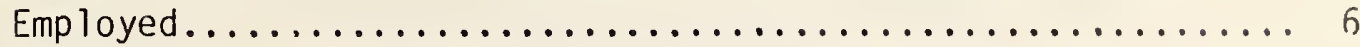

Figure 3 Ionization Current as a Function of Electrode Separation in the Extrapolation Ionization Chamber................. 8

Figure 4 Dependence of Dose Rate on Detector Positioning.......... 10

Figure 5 Variation of Dose Rate with Air Density Close to Sea Level... 12

Figure 6 Degree of Non-Uniformity of Dose Rate over the Horizontal

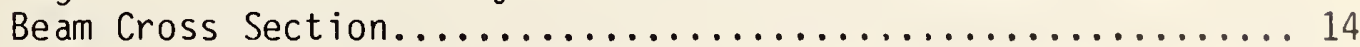

Figure 7 Ionization Current as a Function of Depth in Polyethylene Terephthalate $(\mathrm{PTP}) \ldots \ldots \ldots \ldots \ldots \ldots \ldots \ldots \ldots \ldots \ldots \ldots$

Figure 8 Attenuation Curve in Polystyrene for the $2-m \mathrm{Ci} 90 \mathrm{Sr}+90 \mathrm{Y}$

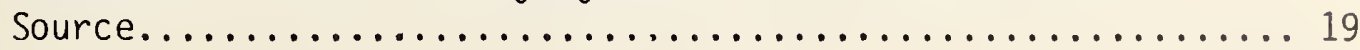

Figure 9 top: Spectrum of ${ }^{147} \mathrm{Pm}$ Source, Used with Flattening Filter. bottom: Spectrum of ${ }^{204} \mathrm{T1}$ Source, Used with Flattening

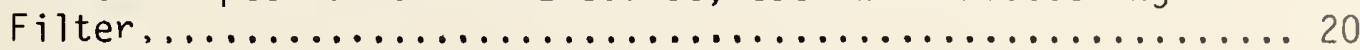

Figure 10 Spectrum of ${ }^{90} \mathrm{Sr}+90 \mathrm{y}$ Sources, Showing Influence of Flatten-

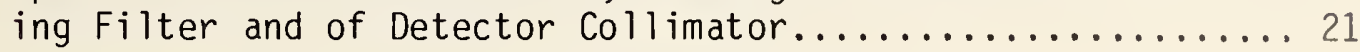

Figure 11 Spectrum of ${ }^{90} \mathrm{Sr}+90 \mathrm{y}$ Sources Used without Flattening Filter, Showing Influence of Source-to-Detector Distance..........? ?2

Figure 12 Effect of Added Polystyrene Absorbers on ${ }^{90} \mathrm{Sr}+90 \mathrm{Y}$ Spectrum... 23

Figure 13 Energy Calibration Spectrum of ${ }^{207} \mathrm{Bi}$ Obtained with the $5-\mathrm{mm}$

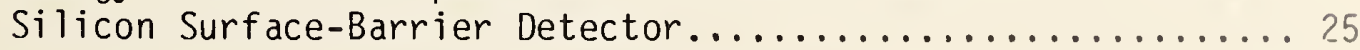

Figure 14 Ionization-versus-Depth Curves for Three Different Types of

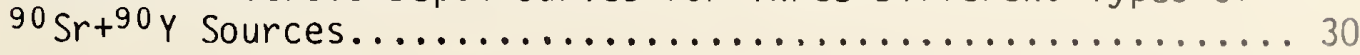

Figure 15 Comparison of Spectrum of Buchler-Amersham and University of Michigan (NVLAP) ${ }^{90} \mathrm{Sr}+9^{90} \gamma$ Sources, on Semi-Logarithmic Scale. 31

Figure 16 Comparison of Spectrum of Amersham Experimental and University of Michigan (NVLAP) $90 \mathrm{Sr}+90 \mathrm{y}$ Sources, on Semi-Logarithmetic Scale. 
Figure 17 Difference between Buchler-Amersham and Amersham Experimental ${ }^{90} \mathrm{Sr}+90$ y Sources, on Semi-Logarithmic Scale.......... 33

Figure 18 Beam-Handling Arrangement, Monoenergetic Electrons........ 35

Figure 19 Degree of Uniformity of Cross Section of Scanned Electron Beam over the Range of Energies and Distances of Interest.... 37

Figure 20 Degradation of Nominal 200-keV, 300-keV, and 400-keV Electrons in Different Thicknesses of Polyimide Added to

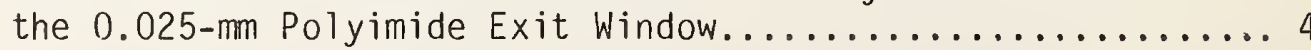

Figure 21 Degradation of Nominal 1.5-MeV and 2.5-MeV Electrons in Different Thicknesses of Aluminum Added to the 0.09-mm Aluminum Exit Window........................... 42

Figure 22 Degradation in Air of Nominal 200-keV to 2.5-MeV Electrons in Different Thicknesses of Intervening Air Layers.........4 43

Figure 23 Response Function of Ionization-Chamber Type Survey Meter to Monoenergetic Electrons Relative to Response to Cs -137 Gamma Radiation............................... 4

Figure 24 Response of Thermoluminescence-Type Personnel Dosimeter to Monoenergetic Electrons Relative to Response to Co-60 Gamma

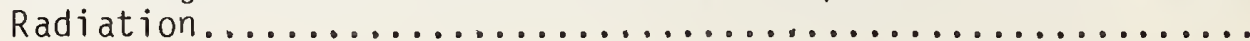

Figure 25 Response of Silicon Surface-Barrier Detector to Monoenergetic Electrons Relative to Beam-Monitor Signal...............448 


\section{LIST OF TABLES}

Page

Table 1 Characteristics of Amersham-Buchler Beta-Particle Sources.... 5

Table 2 Comparison of Absorbed-Dose Rates to Air Obtained by NBS

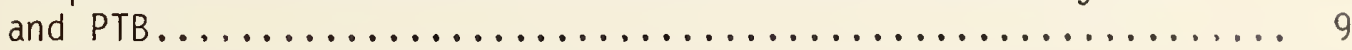

Table 3 Air Density Correction Factor, $\left(1+\alpha x+\beta x^{2}\right) \ldots \ldots \ldots \ldots . . .13$

Table 4 Estimate of Uncertainty in Calibration of Beta-Particle



Table 5 Comparison of Different Types of ${ }^{90} \mathrm{Sr}+{ }^{90} \mathrm{Y}$ Sources..........29

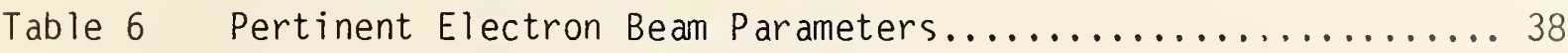

Table 7 Response Characteristics Measured for Three Types of

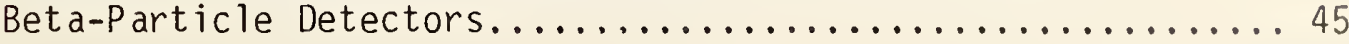

Table 8 Comparison of Directly Measured and Calculated Instrument Response to Beta-Particle Spectra................... 50

Table in Systematic and Statistical Uncertainties.............. 56 Appendix 1 



\section{PREFACE}

During the past few years considerable concern has been expressed within the health physics community as to whether measurements of doses and dose rates from beta radiation are being made with sufficient accuracy to assure protection of workers. One important aspect of such measurements is the calibration of the measurement devices; and accurate calibrations are dependent, among other things, on how accurately the strength of the calibration source is known. Staff personnel at the NRC tend to rely on evidence that the calibration of radiation sources is "traceable to the NBS." When we learned that beta radiation standards were not available at the NBS, we were pleased to provide partial funding to assist the NBS in the purchase and characterization of such standards. This report of subsequent NBS activities toward providing beta radiation standards was prepared by Dr. Margarete Ehrlich, who has been an outstanding contributor to the science and literature of radiation physics for many years. This contribution is no exception.

Division of Radiation Programs and Earth Sciences Office of Nuclear Regulatory Research U.S. Nuclear Regulatory Commission 

1. Introduction

This is the final report on a project established (1) to create at the National Bureau of Standards (NBS) a facility for the calibration of the type of beta-particle sources used in radiation-protection dosimetry and for the study of radiation-protection beta-particle survey and personnel instruments; and (2) to propose guidelines for a secondary calibration laboratory for radiation-protection instrumentation. This project was jointly funded by NBS and the U.S. Nuclear Regulatory Commission (NRC).

The new NBS facility created as a result of this project consists of:

(1) a set of well-characterized beta-particle and near-monoenergetic electron sources covering an energy range from a few hundred kev to above $2 \mathrm{MeV}$;

(2) an extrapolation ionization chamber suited for the determination of absorbed-dose rates to water at distances from the beta-particle and electron sources appropriate for the study of radiation-protection instruments; and

(3) a rugged parallel-plate ionization chamber, calibrated in the betaparticle beams in terms of absorbed-dose rate to water, and suited for use as a transfer instrument that is to establish the traceability to NBS of the beta-particle measurements performed by a secondary-standards laboratory.

One of the reasons why protection measurements for beta particles are considerably more difficult than for photons is the beta particles' vastly greater scattering and absorption in the media intervening between the source and the point of measurement (the "reference point"), and the resulting greater change in beta-particle spectrum - and consequently in detectorresponse characteristics - with the measurement configuration. As a consequence, calibrations of radiation-measurement instruments in beta-particle beams can be considered strictly valid only for the particular configuration 
in which they were performed and are applicable to field measurements in similar configurations only. Conversely, knowledge of the degree to which changes in measurement configuration may produce changes in beam characteristics and therefore in calibration results is of considerable importance. For this reason, the influence on spectral characteristics of the beamflattening filter and other absorbing materials in the beta-particle beams and of changes in source-to-detector distance were investigated, and changes in absorbed-dose rates with barometric pressure were given special attention. Studies of instrument response in beta-particle beams of different spectral characteristics aid in judging the relative merit of these instruments for certain field applications. But because of the strong influence of spectral characteristics on instrument response, it is important to have the capability of measuring instrument response functions with essentially monoenergetic-electron beams, from which the response in any beta-particle field may be deduced if the beta-particle spectrum is known at the reference point. This is why NBS has adapted two of its electron accelerators to supplement - and in part replace - the function of the beta-particle sources for the study of the properties of beta-radiation protection instruments. In the following, the various parts and functions of the new NBS facilities are described in detail; the results of a study of the relationship between the beta-particle fields provided at NBS and those in practical use elsewhere are reviewed; and an attempt is made to predict instrument response to a particular beta-particle spectrum from the instrument's response function obtained with close-to-monoenergetic electrons. Finally, an outline is given of the requirements for secondary standards laboratories through which these and other NBS facilities may contribute to the improvement of the state of radiation-protection dosimetry. 


\section{The NBS Beta-Particle Calibration Facility}

NBS purchased the Amersham-Buchler ${ }^{1}$ beta-particle sources, initially standardized by the Physikalisch-Technische Bundesanstalt (PTB), and the extrapolation ionization chamber designed by the PTB and built for NBS by Pychlau Technical Works. Figure 1 shows a picture of the setup. Information on the properties of the beta-emitting radionuclides employed and on source structure and nominal activity is given in table 1 . Figure 2 shows the approximate theoretical beta-particle spectra of the three radionuclides $[1,2]^{2}$. Following is a discussion of the measurements made to obtain some further properties of interest in the application of these sources in radiationprotection dosimetry.

\subsection{Measurement of Absorbed-Dose Rates}

\subsubsection{Absorbed-dose rates to air}

The extrapolation ionization chamber was used to measure the absorbeddose rate to air for each beta-particle source. Chamber current was found to be a linear function of the separation of the chamber electrodes for separations between 0.1 and $2.5 \mathrm{~mm}$, after suitable corrections had been applied. Four of the five corrections applied (those for ion recombination and

lThroughout this Report, reference to commercial products is made for information only and does not imply that these products are the best or only ones available for the purpose, or that they are endorsed by NBS.

${ }^{2}$ Numbers in brackets indicate the literature references at the end of this report. 


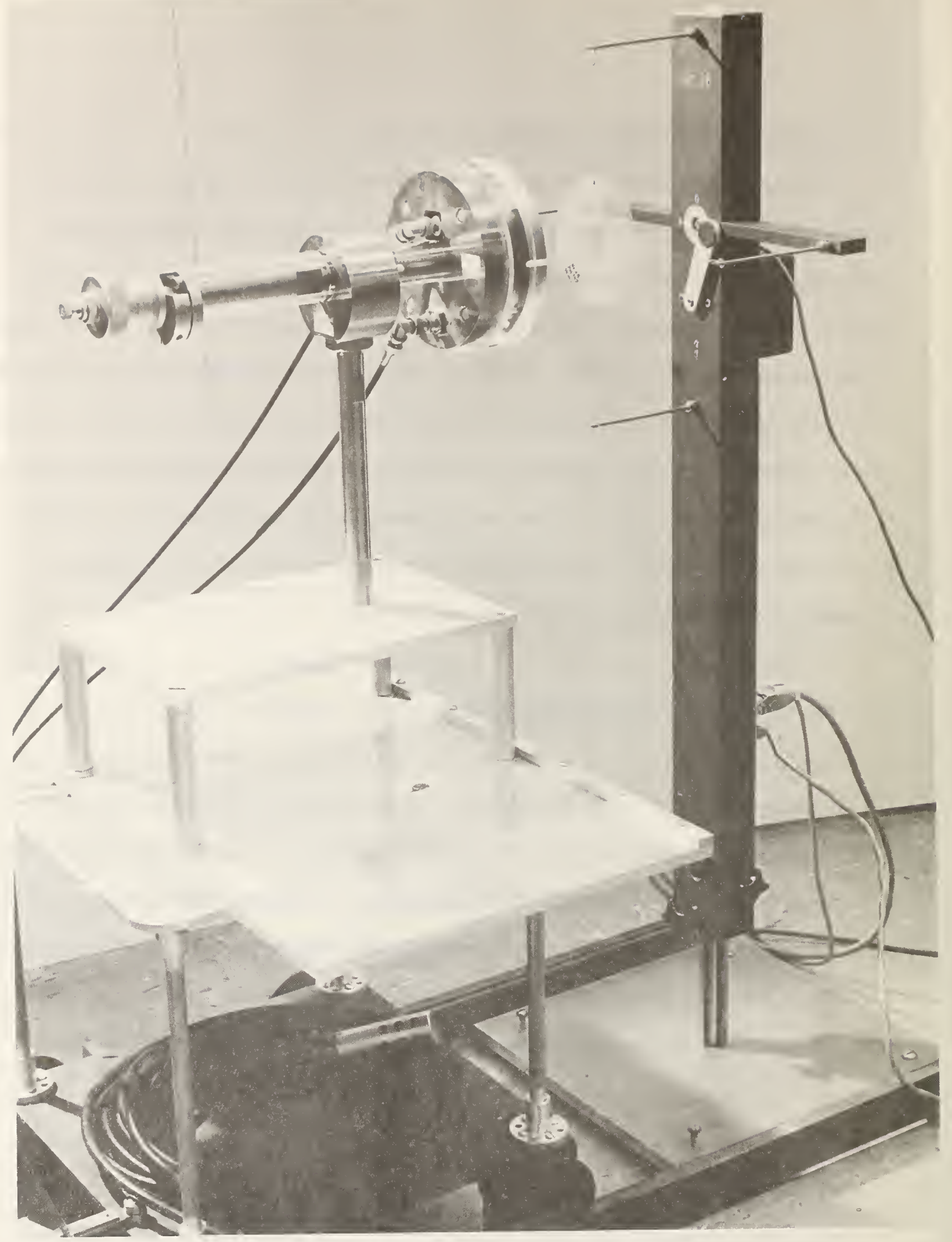

Figure 1. Beta-Particle Calibration Facility. The source-support stand is shown at the right, the extrapolation ionization chamber at the left, and a beam flattening filter supported by wires in-between. The pictured flattening filter is for the $147 \mathrm{Pm}$ source, and is designed for use at the pictured source-to chamber distance of $20 \mathrm{~cm}$. The source shutter is electrically interlocked, with photocells defining a safety perimeter as long as the shutter is open, as shown. 
Table 1. Characteristics of Amersham-Buchler Beta-Particle Sources

(a) Source Structure and Activity

\begin{tabular}{|c|c|c|c|c|}
\hline Radionuclide & Half Life & Structure & $\begin{array}{c}\text { Source } \\
\text { Encapsulation }\end{array}$ & $\begin{array}{l}\text { Nominal Activity } \\
\mathrm{MBq}(\mathrm{mC} i) \text {; date }\end{array}$ \\
\hline${ }^{90} \mathrm{~S} r+90 \mathrm{Y}$ & $28.5 y$ & $\begin{array}{l}{ }^{90} \mathrm{Sr} \text { carbonate } \\
\text { pressed }{ }^{\mathrm{b}} \text { into } \\
\mathrm{Ag} \text { foil }\end{array}$ & $\begin{array}{l}50 \mathrm{mg} / \mathrm{cm}^{2} \mathrm{Ag} \\
+0.1 \mathrm{~mm}\left(77 \mathrm{mg} / \mathrm{cm}^{2}\right) \\
\text { steel }\end{array}$ & $\begin{array}{l}\text { 1850(50); } \\
\quad \text { May 24, } 1982\end{array}$ \\
\hline $90 S r+90 \gamma$ & $28.5 y$ & $\begin{array}{l}90 \mathrm{Sr} \text { carbonate } \\
\text { pressed }{ }^{\mathrm{b}} \text { into } \\
\mathrm{Ag} \text { foil }\end{array}$ & $\begin{array}{l}50 \mathrm{mg} / \mathrm{cm}^{2} \mathrm{Ag} \\
+0.1 \mathrm{~mm}\left(77 \mathrm{mg} / \mathrm{cm}^{2}\right) \\
\text { steel }\end{array}$ & $\begin{array}{l}74(2) ; \\
\quad \text { Dec } 16,1982\end{array}$ \\
\hline $204 \mathrm{T1}$ & $3.78 y$ & $\begin{array}{l}{ }^{204} \mathrm{Tl} \text { pressed }^{\mathrm{b}} \\
\text { into } \mathrm{Ag} \text { foil }\end{array}$ & $20 \mathrm{mg} / \mathrm{cm}^{2} \mathrm{Ag}$ & $\begin{array}{l}\text { 18.5(0.5); } \\
\quad \text { Dec 16, } 1982\end{array}$ \\
\hline $147 \mathrm{Pm}$ & $2.62 y$ & $\begin{array}{l}{ }^{147} \mathrm{Pm} \text { pressed } \\
\text { into } \mathrm{Ag} \text { foil }\end{array}$ & $5 \mathrm{mg} / \mathrm{cm}^{2} \mathrm{Ag}$ & $\begin{array}{l}\text { 518(14); } \\
\quad \text { Dec 16, } 1982\end{array}$ \\
\hline
\end{tabular}

(b) Beta-Particle Energies and Ranges

\begin{tabular}{|c|c|c|c|c|c|}
\hline \multirow[t]{3}{*}{ Radionuclide } & \multirow{3}{*}{$\begin{array}{l}\text { Avg. and Max. } \\
\text { Beta-Particle } \\
\text { Energies (MeV) }{ }^{\mathrm{C}}\end{array}$} & \multicolumn{4}{|c|}{ Range in } \\
\hline & & \multicolumn{2}{|c|}{ air } & \multicolumn{2}{|c|}{ polystyrene } \\
\hline & & $\mathrm{cm}$ & $\mathrm{mg} / \mathrm{cm}^{2}$ & $\mathrm{~cm}$ & $\mathrm{mg} / \mathrm{cm}^{2}$ \\
\hline${ }^{90} S r^{d}$ & $\begin{array}{l}\bar{E}=0.196 \\
E_{\max }=0.546\end{array}$ & $\begin{array}{r}41 \\
187\end{array}$ & $\begin{array}{r}49 \\
225\end{array}$ & 0.19 & 204 \\
\hline $90 \mathrm{Y}$ & $\begin{array}{l}\bar{E}=0.935 \\
E_{\max }=2.284\end{array}$ & $\begin{array}{r}375 \\
1037\end{array}$ & $\begin{array}{r}452 \\
1249\end{array}$ & 1.10 & 1167 \\
\hline${ }^{204} \mathrm{~T} 1$ & $\begin{array}{l}\bar{E}=0.244 \\
E_{\max }=0.763\end{array}$ & $\begin{array}{r}58 \\
291\end{array}$ & $\begin{array}{r}70 \\
351\end{array}$ & 0.30 & 319 \\
\hline $147 \mathrm{Pm}$ & $\begin{array}{l}\bar{E}=0.062 \\
E_{\max }=0.225\end{array}$ & $\begin{array}{l}5.9 \\
51\end{array}$ & $\begin{array}{r}7.2 \\
61\end{array}$ & 0.052 & 55 \\
\hline
\end{tabular}

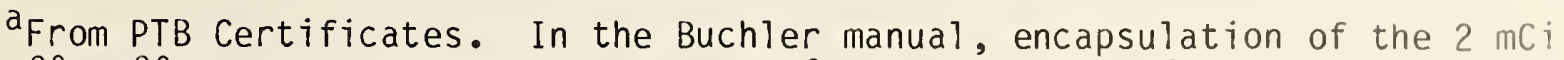
${ }^{90} \mathrm{Sr}+90 \mathrm{y}$ source is 1 isted as $50 \mathrm{mg} / \mathrm{cm}^{2} \mathrm{Ag}$ plus $1 \mathrm{mg} / \mathrm{cm}^{2} \mathrm{Au}$.

bouring the rolling stage.

${ }^{C_{A v}}$ verage and maximum energies are for ideal point sources.

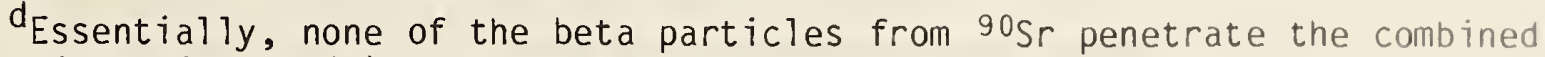
filtration of (1) the source encapsulation, (2) the air between source and detector, and (3) the beam-flattening filter. 


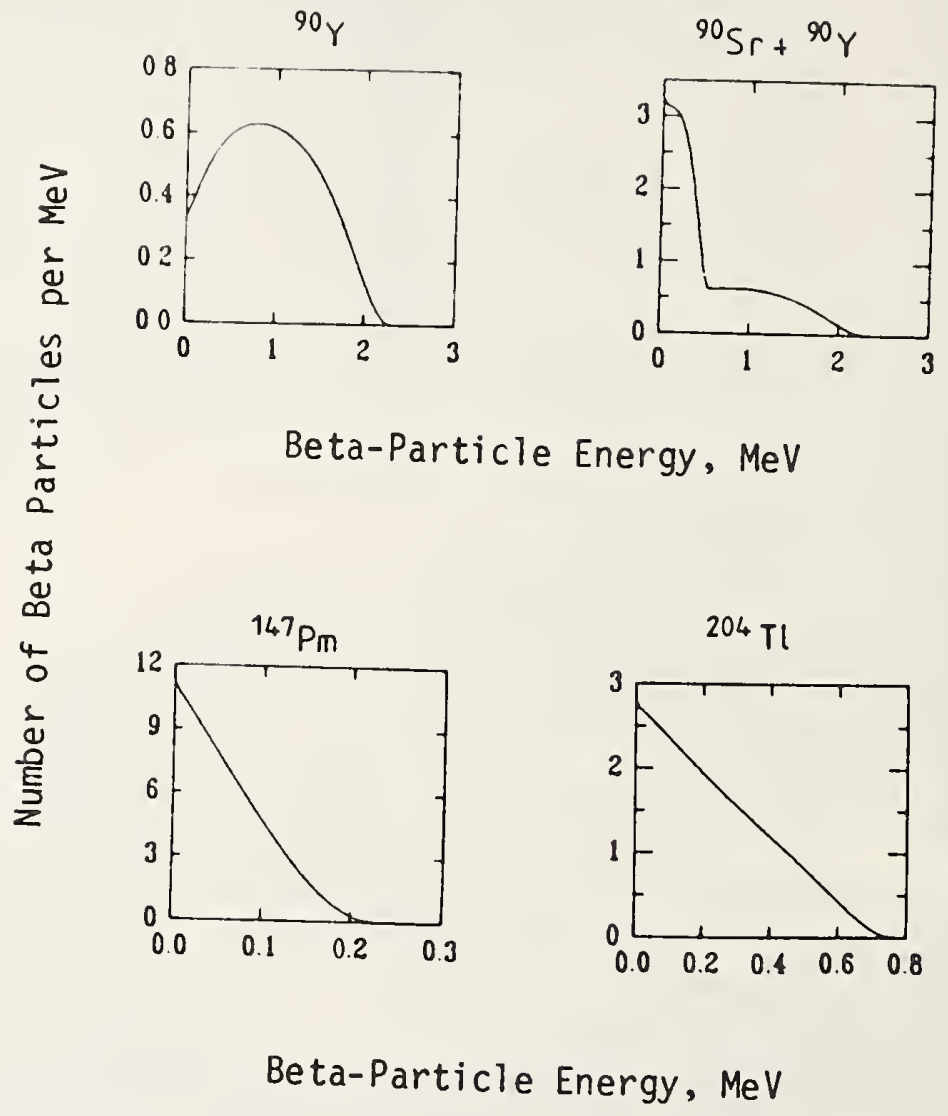

Figure 2. Theoretical Beta-Particle Spectra for the Radionuclides Employed [2]. Plotted is the number of beta particles per MeV for one transition from the original state, against beta-particle energy in MeV. 
diffusion, for air-density variations inside the chamber, for beam scattering by the side walls of the chamber, and for beam attenuation by the chamber's beam-entrance window) were taken from the literature [3-5]. The correction required for variations of air density outside the ionization chamber was measured [6]. (See also 2.1.2b.)

Figure 3 shows the fully corrected ionization currents as a function of electrode-plate separation. The slopes of the curves were used to determine the corresponding absorbed-dose rate to air at the front surface of the chamber. Table 2 gives a comparison of the results with those obtained by the PTB for the same sources in similar geometries.

\subsubsection{Uncertainty in the Determination of Absorbed-Dose Rate to Air}

In order to arrive at the uncertainty in the absorbed-dose rate determinations, measurements were made of the variation of dose rate with sourceto-detector distance and with air density, and of the degree of non-uniformity of the dose rate over the beam cross section. For each of the parameters investigated, the variations were found to be largest for ${ }^{147} \mathrm{Pm}$, indicating that $147 \mathrm{Pm}$ calibrations will be the least reliable. This conclusion is supported by a comparison of the magnitude of the correction for beam attenuation in the entrance window of the chamber, taken from the literature. While for ${ }^{90 S r+90 Y}$ and for $204 \mathrm{Tl}$ the correction is less than 2 percent, it is almost a factor of two for $147 \mathrm{Pm}$, i.e., only about one-half of the beta particles penetrate the window of the extrapolation chamber. The results of the measurements are discussed below in grater detail:

(a) Dependence of dose rate on detector positioning. Figure 4 shows that positioning of the detector is not too critical for any but the $14 / \mathrm{Pm}$ source, for which a change in distance by $5 \mathrm{~mm}$ causes a change in dose rate by close 


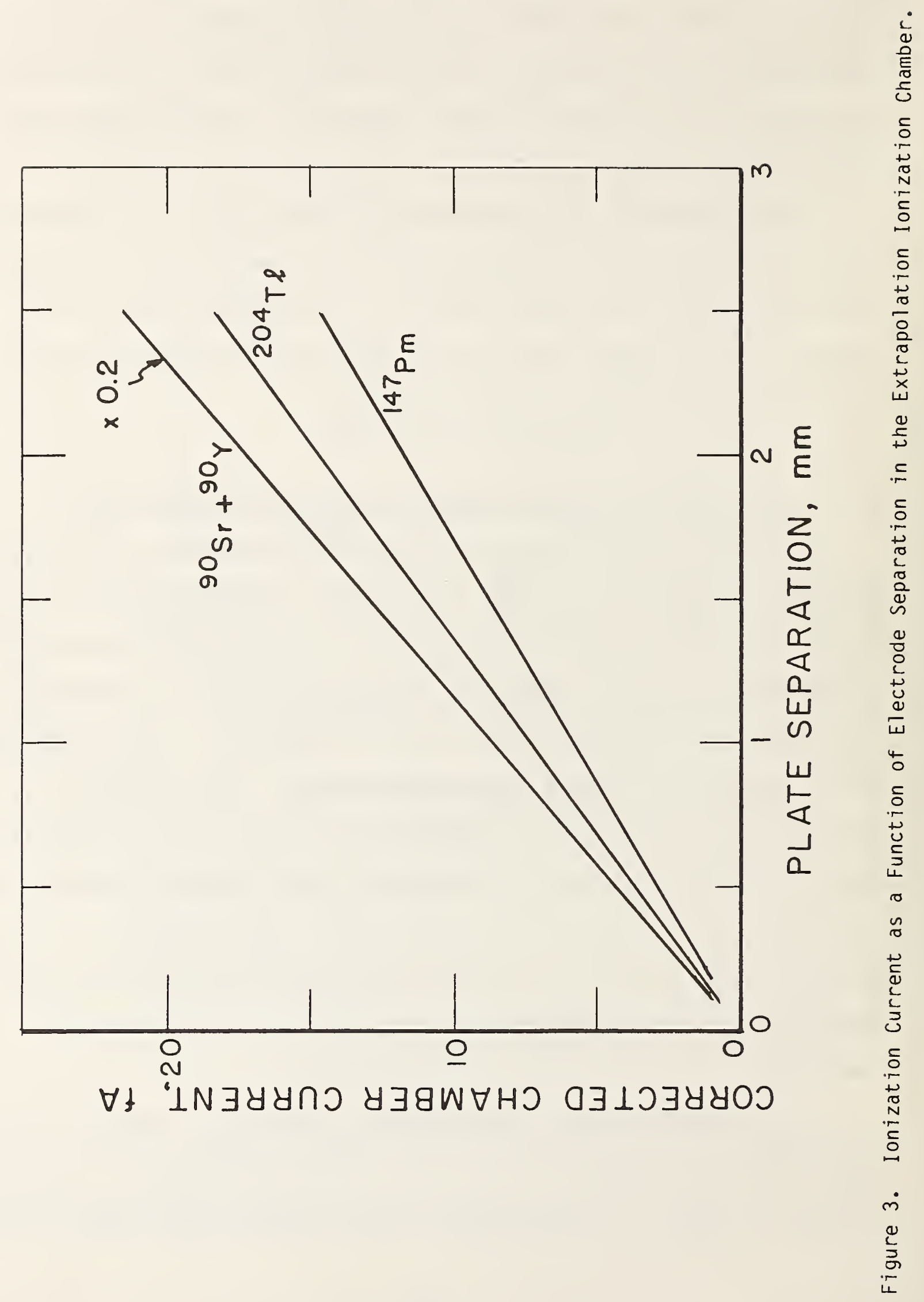


Table 2. Comparison of Absorbed-Dose Rates to Air Obtained by NBS and PTB.

\begin{tabular}{|c|c|c|c|c|c|}
\hline \multicolumn{2}{|c|}{ Source } & \multicolumn{4}{|c|}{ Absorbed Dose Rate } \\
\hline \multirow{2}{*}{ Type } & \multirow{2}{*}{$\begin{array}{l}\text { Nominal } \\
\text { activity } \\
\quad(\mathrm{mCi})\end{array}$} & \multirow{2}{*}{$\begin{array}{c}\text { At source-to- } \\
\text { detector distance } \\
(\mathrm{cm})\end{array}$} & \multicolumn{2}{|c|}{$\mu G y / s^{a}$} & \multirow{2}{*}{$\begin{array}{l}\text { Ratio } \\
\text { NBS/PTB }\end{array}$} \\
\hline & & & NBS & PTB & \\
\hline $147 \mathrm{Pm}$ & 14 & 20 & 0.234 & 0.227 & 1.03 \\
\hline $204 \mathrm{Tl}$ & 0.5 & 30 & 0.293 & 0.293 & 1.00 \\
\hline $90 S r+90 y$ & 2 & 30 & 1.707 & 1.685 & 1.01 \\
\hline$"$ & 50 & 11 & 451 & 449 & 1.01 \\
\hline$"$ & $"$ & 30 & 62.4 & 61.9 & 1.01 \\
\hline " & " & 50 & 22.4 & 22.2 & 1.01 \\
\hline
\end{tabular}

a Referred to January $1,1983,20^{\circ} \mathrm{C}$, and $760 \mathrm{mmHg}$. 


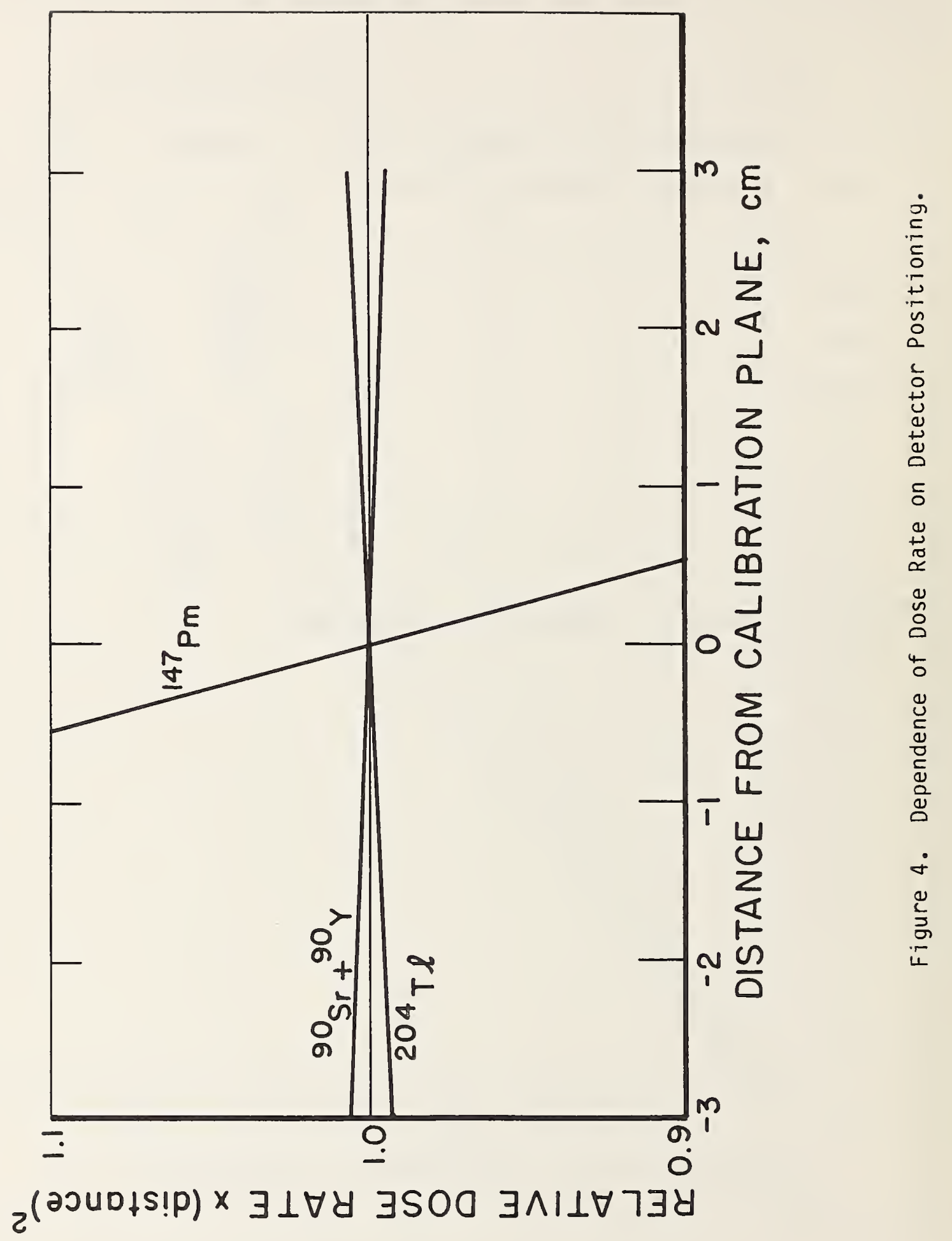


to 10 percent. As a consequence, there will be a significant dose-rate gradient over the sensitive volume of a survey meter in the $14 / \mathrm{Pm}$ betaparticle beam, if this volume extends over more than just a few millimeters.

(b) Variation of dose rate with air pressure. Figure 5 shows the variation of dose rate with the reciprocal of the air density for the three types of beta-particle sources measured at NBS, located at an altitude close to sea level. For $147 \mathrm{Pm}$, there is a 10 -percent change in dose rate for a change in atmospheric pressure of less than 2 percent. No appreciable change in dose rate was observed with the $204 \mathrm{Tl}$ and $90 \mathrm{Sr}+90 \mathrm{Y}$ sources for a change in barometric pressure amounting to 4 percent. The air-density corrections measured by the PTB and provided with the sources compensate adequately for this effect, but they are not suited for use with sources at a laboratory situated at a much higher altitude. For this reason, NBS carried out measurements over a wide range of barometric pressures in an environmenta] chamber. [6] Table 3 shows the resulting correction factors for calibrations carried out at sea level for sources to be used at higher altitudes. These corrections were checked by actual measurements on a $147 \mathrm{Pm}$ source at an elevation of $\sim 1500 \mathrm{~m}$ above sea level. The measured absorbed-dose rate, corrected for the difference in altitude, was found to agree to within the experimental uncertainty $( \pm 3 \%)$ with the dose rate that had been measured for this source at the PTB, located near sea level.

(c) Degree of non-uniformity of dose rate over the beam cross section. Typical results of this study are shown in figure 6 . Along the horizontal line passing through the center of the beam cross section, the points of equal dose rate are seen to be distributed symmetrically about the beam center for ${ }^{90} \mathrm{~S} r+90 \mathrm{Y}$ and for $204 \mathrm{Tl}$, the dose rates varying by less than \pm 1 percent and \pm 2 percent, respectively, for points $10 \mathrm{~cm}$ off the central beam axes of these 


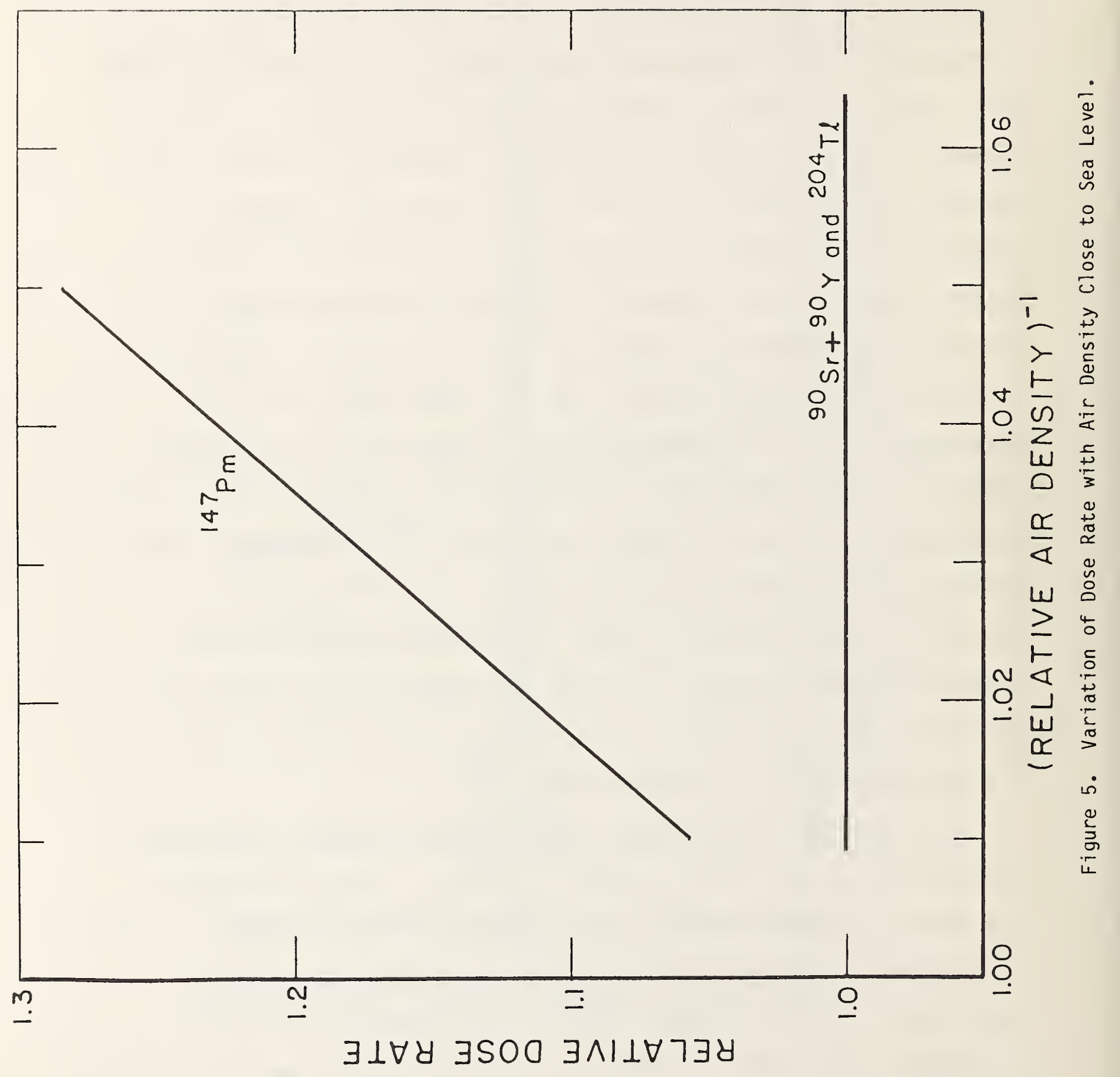


Table 3. Air Density Correction Factor, $\left(1+\alpha x+\beta x^{2}\right)$

The variable $x$ stands for the quantity $\left(1-\rho / \rho_{0}\right)$, where $\rho_{0}$ is the reference air density and $\rho$ is the air density at the point of measurement. The coefficients $\alpha$ and $\beta$ are given below for the four sources and three depths in a plastic absorber, from which the correction factor for the depths and environmental conditions of interest may be computed.

\begin{tabular}{|c|c|c|c|c|c|c|}
\hline Nuclide & $\begin{array}{c}\text { Nominal } \\
\text { Activity } \\
(\mathrm{MBq})\end{array}$ & $\begin{array}{c}\text { Absorber } \\
\text { Deptha } \\
\left(\mathrm{mg} / \mathrm{cm}^{2}\right)\end{array}$ & $\begin{array}{l}\text { No. of } \\
\text { Data } \\
\text { Sets }\end{array}$ & $\alpha$ & B & $\begin{array}{c}\sigma \\
(\%)\end{array}$ \\
\hline \multirow{3}{*}{$147 \mathrm{Pm}^{\mathrm{b}}$} & \multirow[t]{3}{*}{500} & 2.6 & 20 & 4.8 & 12.6 & 3 \\
\hline & & 6.3 & 9 & 3.5 & 19.8 & 4 \\
\hline & & 10.1 & 9 & 0.7 & 31.3 & 10 \\
\hline \multirow{3}{*}{$204 T 7^{b}$} & \multirow[t]{3}{*}{20} & 2.6 & 30 & 0.17 & -0.52 & 0.9 \\
\hline & & 6.3 & 9 & 0.13 & -0.33 & 0.4 \\
\hline & & 46.2 & 11 & 0.14 & 0.48 & 2 \\
\hline \multirow{3}{*}{$90 S r+90 \gamma^{b}$} & \multirow[t]{3}{*}{80} & 2.6 & 14 & -0.08 & -0.03 & 0.6 \\
\hline & & 6.3 & 11 & -0.06 & -0.18 & 0.2 \\
\hline & & 46.2 & 10 & 0.04 & -0.28 & 0.4 \\
\hline \multirow{3}{*}{${ }^{90} S r+90 \gamma c$} & \multirow[t]{3}{*}{2000} & 2.6 & 11 & 0.12 & -0.50 & 0.3 \\
\hline & & 46.2 & 10 & 0.07 & -0.18 & 0.2 \\
\hline & & 318.0 & 21 & 0.25 & -0.39 & 0.2 \\
\hline
\end{tabular}

aThickness of polyethylene terepthalate (PTP) absorber in front of the extrapolation chamber air gap for all but the $318 \mathrm{mg} / \mathrm{cm}^{2} \mathrm{depth}$, for which $315 \mathrm{mg} / \mathrm{cm}^{2}$ of polystyrene was used in front of the $2.6 \mathrm{mg} / \mathrm{cm}^{2}$ extrapolationchamber window.

bith flattening filter, at the prescribed source-to-detector distance (see Table 2).

Without flattening filter, at a $30-\mathrm{cm}$ source-to-detector distance. 


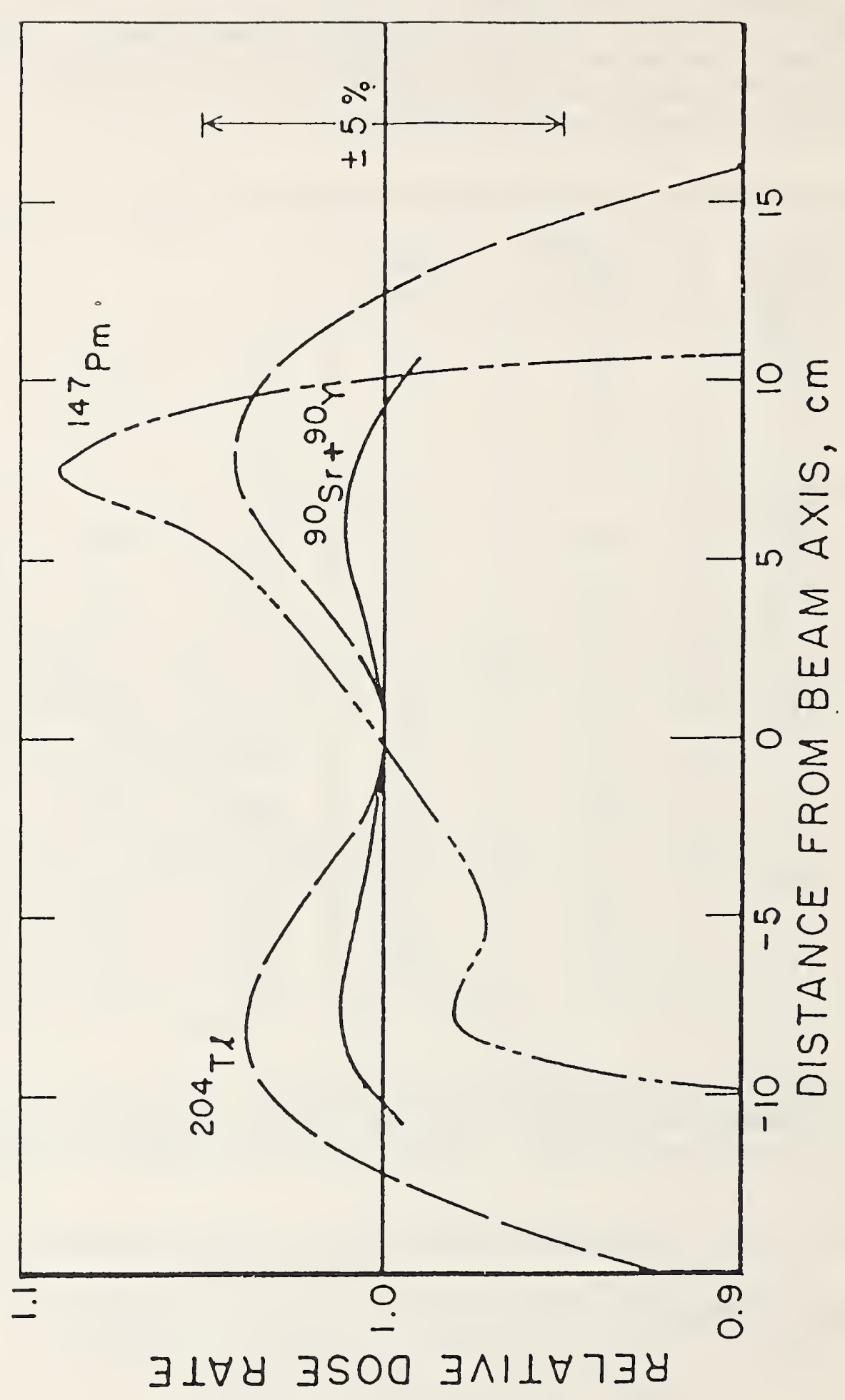

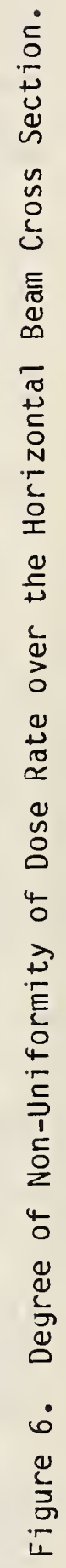


two sources. For $147 \mathrm{Pm}$, the points of equal dose rate are asymmetrically distributed, the variation in dose rate amounting to about \pm 10 percent for points up to $10 \mathrm{~cm}$ removed from the central beam axis ( \pm 6 percent for points removed by not more than $\sim 8 \mathrm{~cm}$ ). The asymmetry evident in the $147 \mathrm{Pm}$ beam cross section may be caused by the shutter of the source holder, and probably can be reduced.

(d) Estimate of overall measurement uncertainty. Table 4 shows estimates for the uncertainties in the calibration of the NBS beta-particle sources. Since these uncertainties are mainly associated with the measurement process proper, they also hold for the calibration of sources submitted to NBS by others, provided that the degree of non-uniformity of the beam cross section of these sources is similar. Appendix 1 gives a detailed discussion of how the values given in table 4 were obtained. Further uncertainties arise in the study of radiation-protection instruments mainly because of limitations in the reproducibility of the response of these instruments and the larger size of their sensitive volumes.

\subsubsection{Determination of Absorbed-Dose Rate to Plastic as a Function of Depth in Plastic}

In order to arrive at the shallow and deep absorbed-dose rates to plastic (which, for protection purposes, may be set equal to absorbed-dose rates to tissue) measurements were made of ionization current in the extrapolation ionization chamber as a function of thickness of polyethylene terephthalate (PTP) added to the $2.6-\mathrm{mg} / \mathrm{cm}^{2}$ window of the chamber. The results are shown in figure 7 for all three types of beta-particle sources. For $147 \mathrm{Pm}$, the decrease in current with PTP thickness is roughly exponential from the onset, and absorption is essentially complete after an addition of $\sim 20 \mathrm{mg} / \mathrm{cm}^{2}$ of 
Table 4. Estimate of Uncertainty in Calibration of Beta-Particle Sources

\begin{tabular}{l|c|c}
\hline \multicolumn{1}{c|}{ Quantity } & \multicolumn{1}{c}{ Uncertainty } \\
\hline $\begin{array}{l}\text { Corrected ionization current per } \\
\text { unit air gap, measured for four } \\
\text { separate setups and five air gaps } \\
\text { per setup } c\end{array}$ & Systematic & Statistical \\
\hline $\begin{array}{l}\text { Absorbed dose to water } \\
\text { (computed from ionization current) }\end{array}$ & $0.6 \%$ & 147Pm: $1.2 \%$ \\
\hline
\end{tabular}

${ }^{a}$ Components combined as the square root of the sum of their squares.

${ }^{b}$ Estimated from a plot of ionization current-versus-air gap (19 degrees of freedom, on the average) as three times the standard deviation computed from the residuals of the least-squares fit of a straight line to the data points.

${ }^{c}$ Includes uncertainty in positioning the ionization chamber relative to the source and installing the flattening filter, if any. 


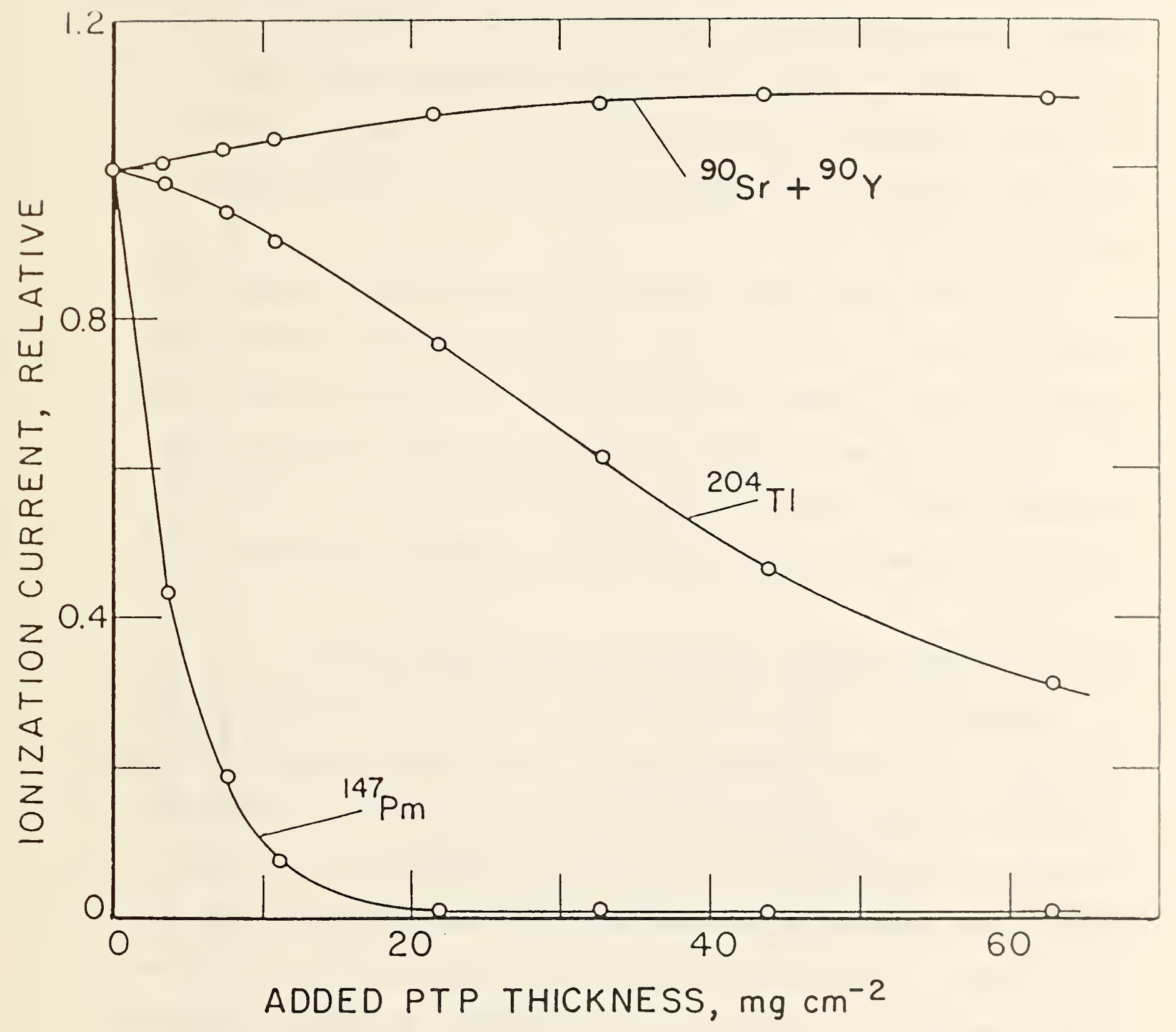

Figure 7. Ionization Current as a Function of Depth in Polyethylene Terephthalate (PTP). 
PTP. For larger thicknesses, the ionization current remains at $\sim 1$ percent of the maximum current, probably indicating the level of bremsstrahlung produced by the ${ }^{147} \mathrm{Pm}$ beta particles in the PTP and of the $121-\mathrm{keV}$ gamma rays from $147 \mathrm{Pm}$. For ${ }^{90} \mathrm{Sr}+90 \mathrm{y}$, there is an ionization buildup over the first $\sim 40 \mathrm{mg} / \mathrm{cm}^{2}$ of added PTP before attenuation starts to dominate, while for ${ }^{204} \mathrm{Tl}$ the attenuation in PTP seems partially offset by buildup over the first added. $\sim 15 \mathrm{mg} / \mathrm{cm}^{2}$ of PTP.

Because PTP is not readily adaptable to measurements at laryer thicknesses, attenuation curves for ${ }^{90} \mathrm{~S} r+90 \mathrm{y}$ were also obtained with added polystyrene, covering a range of thicknesses from $\sim 100 \mathrm{mg} / \mathrm{cm}^{2}$ to beyond $2 \mathrm{~g} / \mathrm{cm}^{2}$. The results are shown in figure 8 , demonstrating that any bremsstrahlung background (ionization-current contribution by the source for polystyrene thicknesses beyond the beta-particle range) is less than 0.06 percent.

\subsection{Beta-Particle Spectral Composition at the Reference Point}

Because of the emphasis on the change in spectral characteristics with changes in certain experimental parameters rather than on spectral characteristics per se, these studies were confined to a comparison of pulse-height distributions, obtained with a given detector and converted to an absolute energy scale, ignoring certain spectral distortions introduced by the detector. Figures 9 through 12 show these spectral distributions for the three types of sources. (No difference was found between the spectra of the 2-mCi and the 50-mCi ${ }^{90} \mathrm{Sr}+90 \mathrm{y}$ sources used in the same geometry.) The spectra were obtained with a 5-mm deep silicon surface-barrier detector operated at room temperature, in air, under a cover of $0.013 \mathrm{~mm}$ of aluminized PTP for light protection. A low-scatter $207 \mathrm{Bi}$ point source (NBS Standard Reference Materia) 4240) was used for the energy calibration (pulse-height-to-energy conversion). 


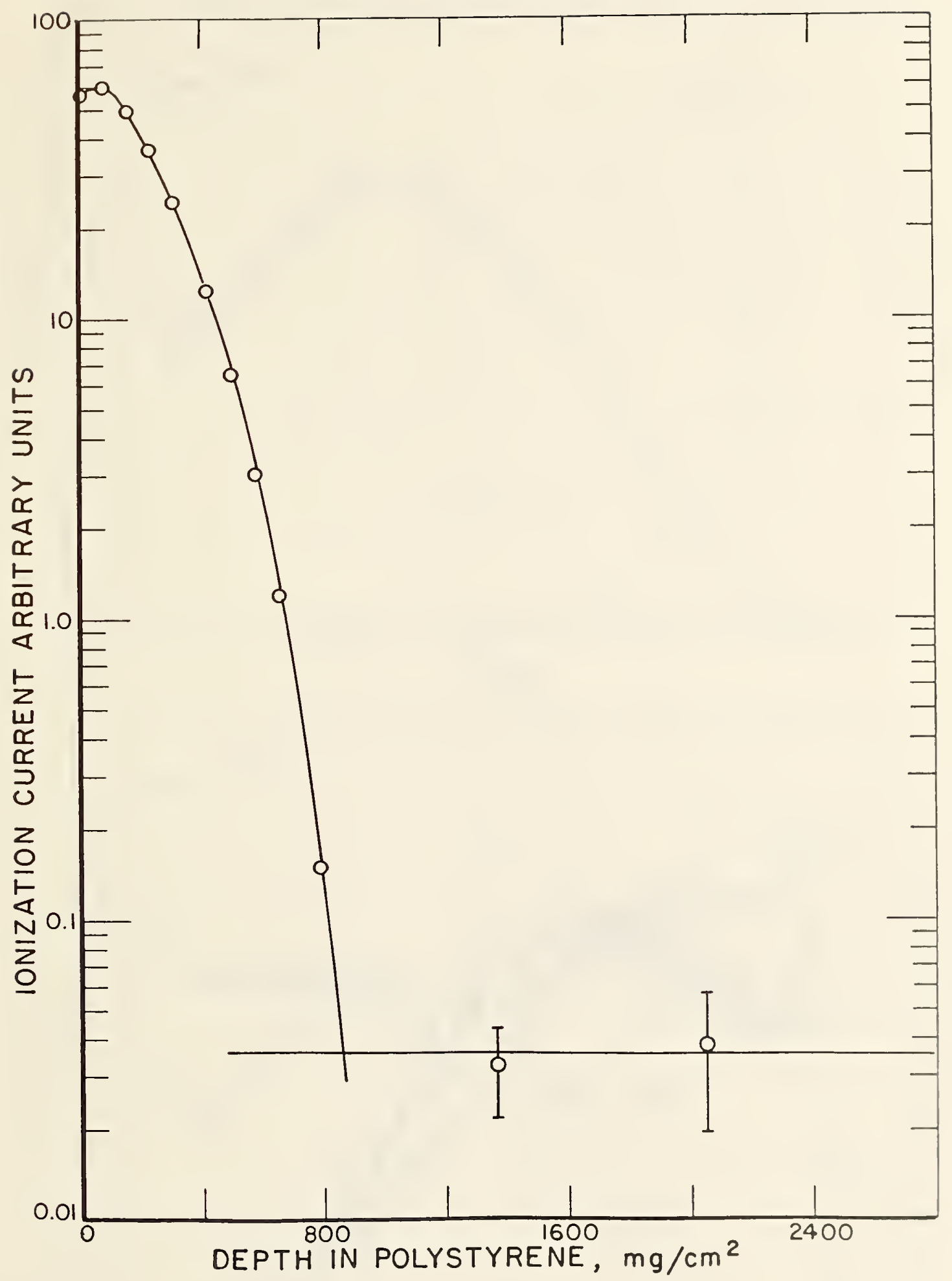

Figure 8. Attenuation Curve in Polystyrene for the 2-mCi $90 \mathrm{Sr}+90 \mathrm{y}$ Source. 

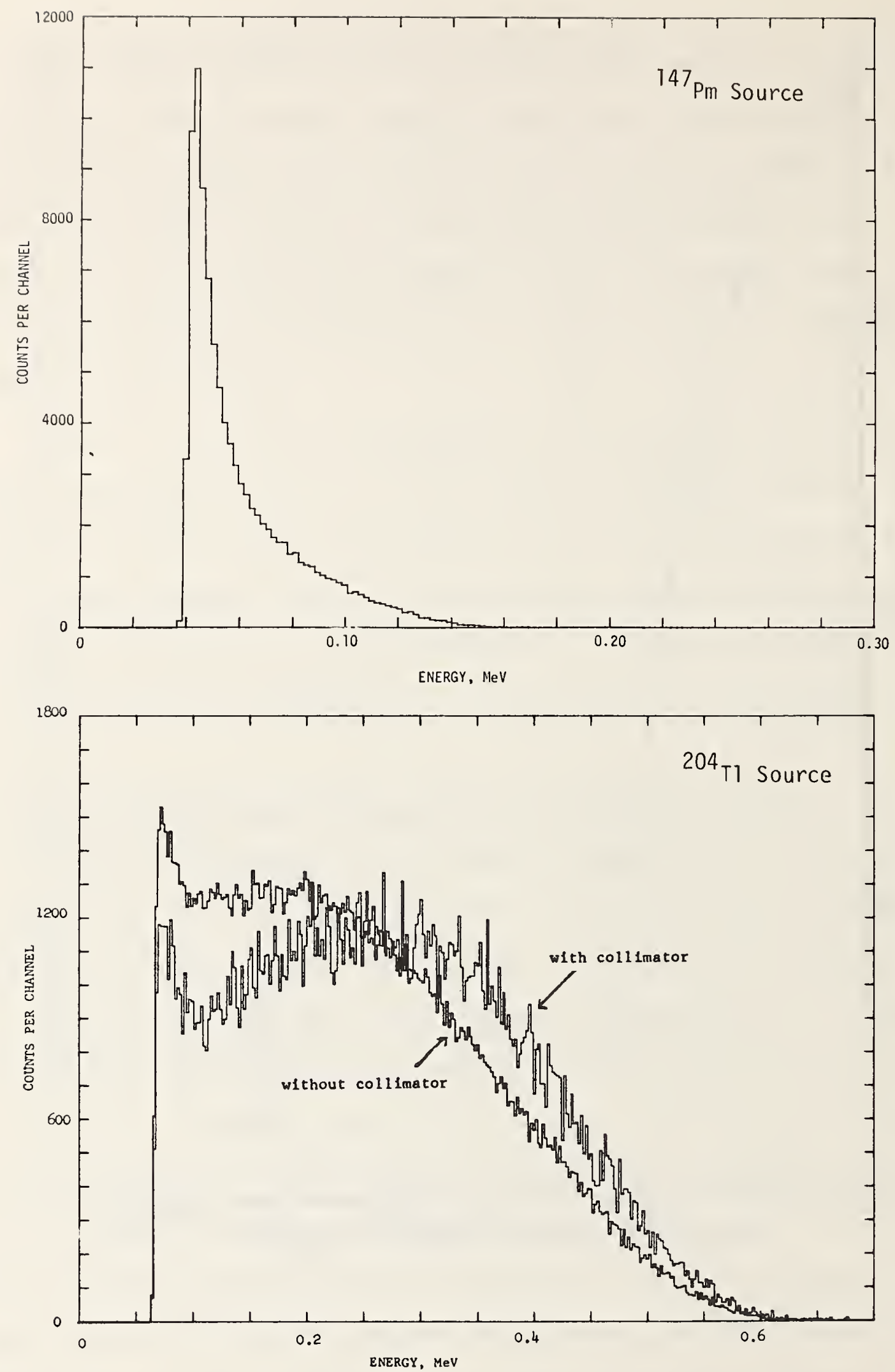

Figure 9. top: Spectrum of ${ }^{147} \mathrm{Pm}$ Source, Used with Flattening Filter. Distance: $20 \mathrm{~cm}$; Detector Uncollimated.

bottom: Spectrum of $204 \mathrm{Ti}$ Source, Used with Flattening Filter, Showing Influence of Lead Collimator with Circular Aperture, $3.2 \mathrm{~mm}$ in Diameter. Distance: $30 \mathrm{~cm}$. 

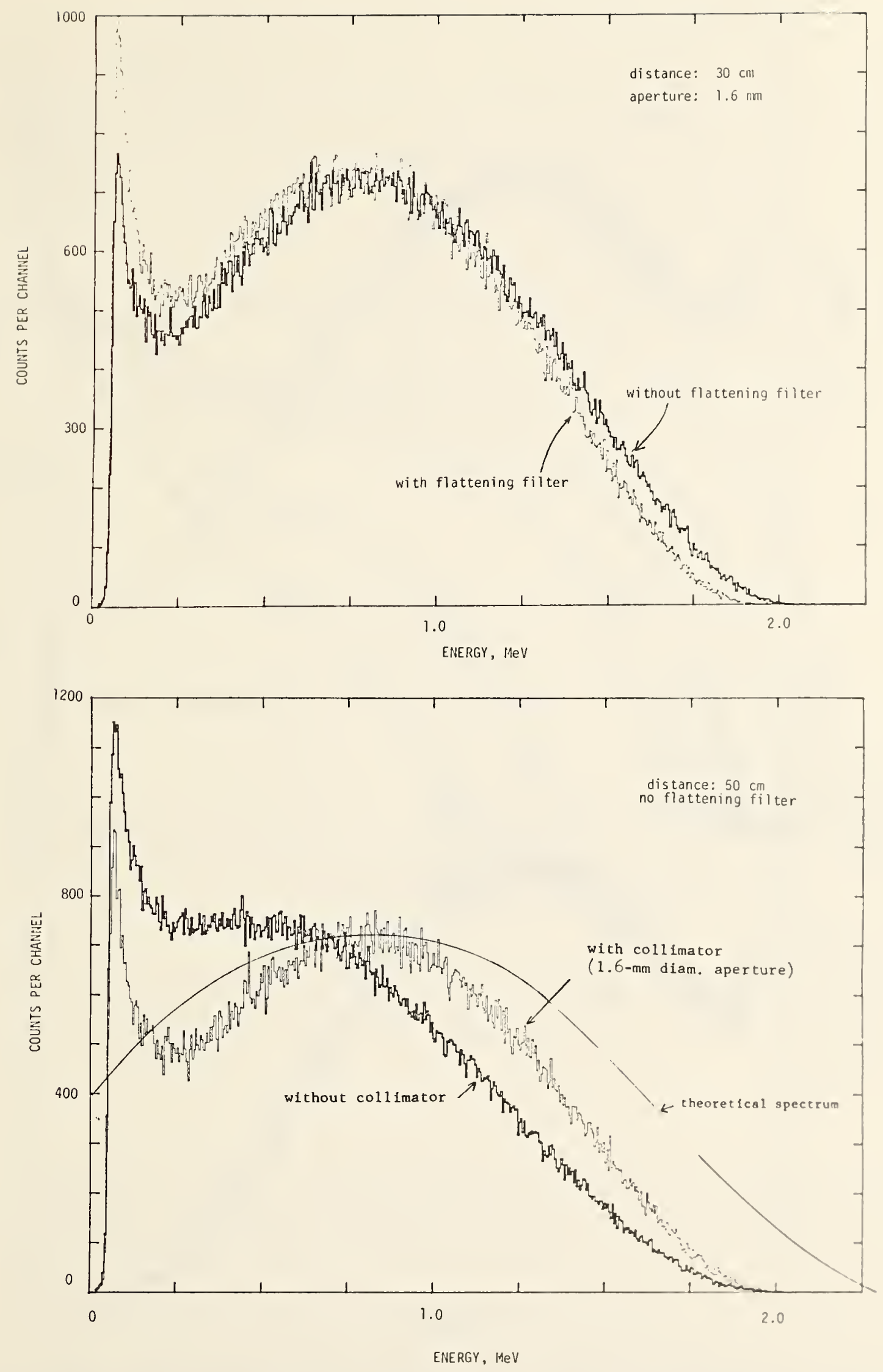

Figure 10. Spectrum of ${ }^{90} \mathrm{Sr}+90 \mathrm{y}$ Sources, Showing Influence of Flattening Filter and of Detector Collimator. The Theoretical Spectrum of $90 y$ is Shown for Comparison. 

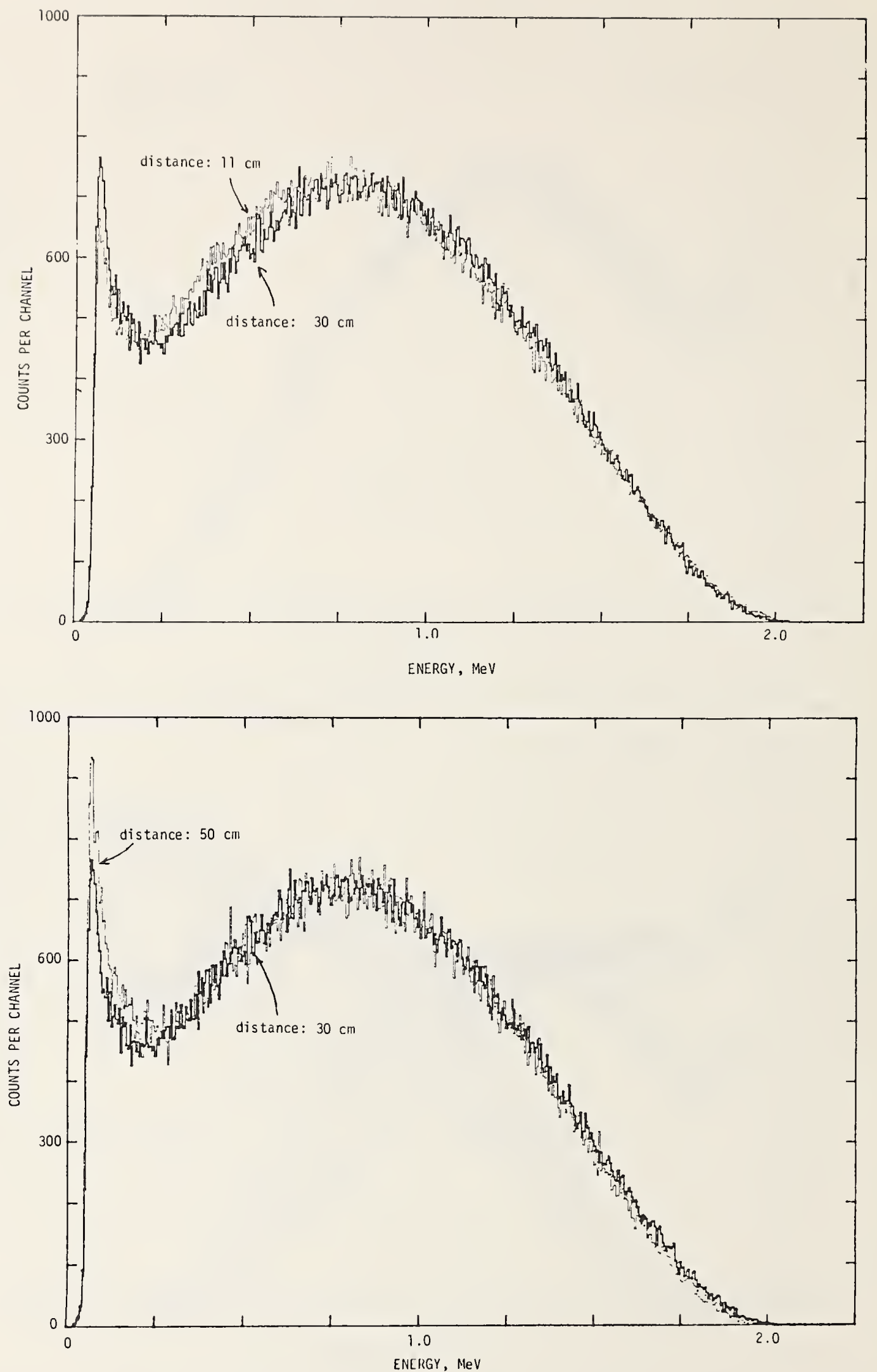

Figure 11. Spectrum of $90 \mathrm{Sr}+90 \mathrm{y}$ Sources Used without Flattening Filter, Showing Influence of Source-to-Detector distance. Detector Collimator: Circular Aperture, 1.6-mm in Diameter. 


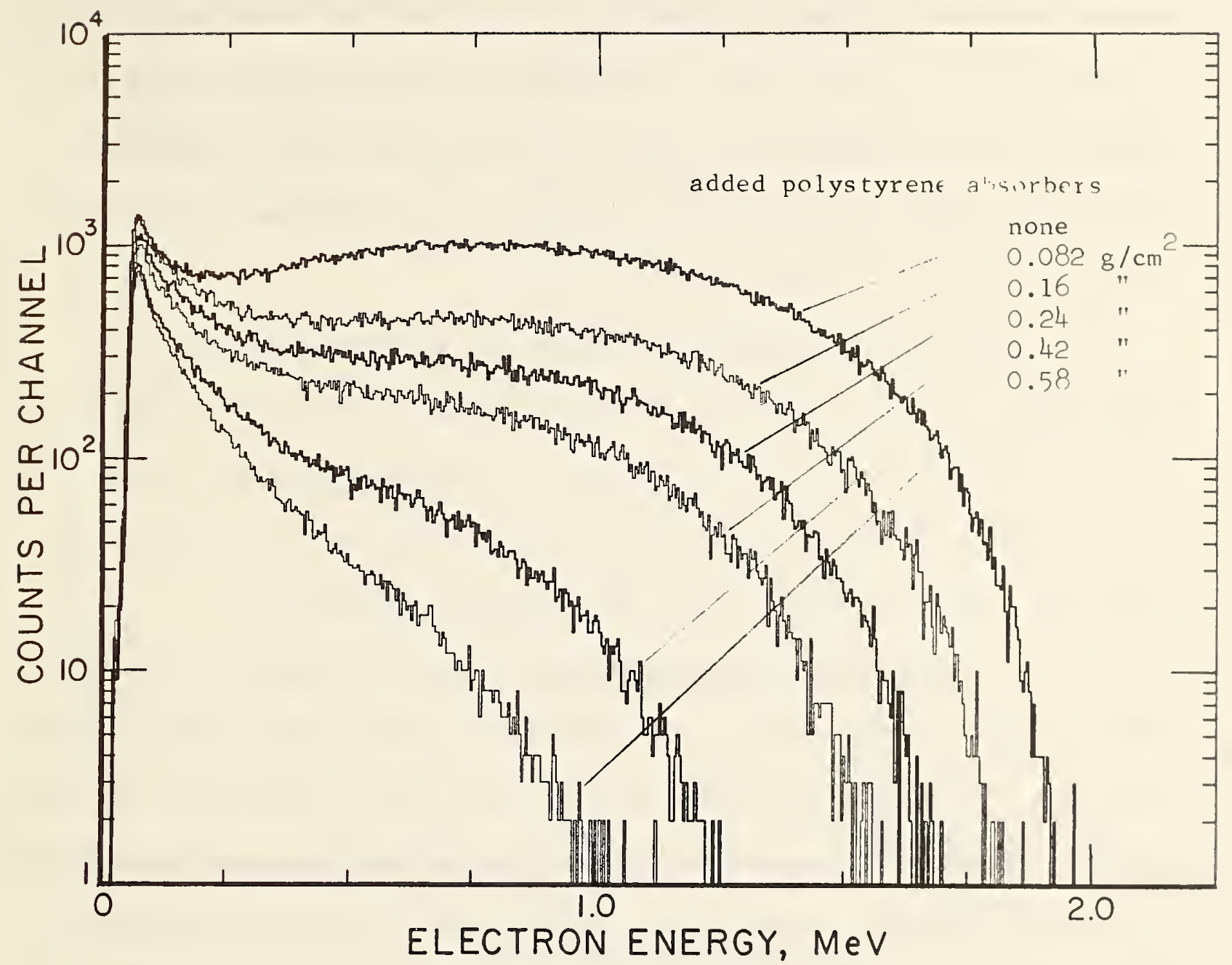

Figure 12. Effect of Added Polystyrene Absorbers on $90 \mathrm{Sr}+90 \mathrm{y}$ Spectrum. Detector Collimator: Circular Aperture, $1.6 \mathrm{~mm}$ in Diameter. 
The pulse-height distribution obtained with this source using the surfacebarrier detector is shown in figure 13. For all but the ${ }^{147} \mathrm{Pm}$ source, a lead collimator with a $1.6-\mathrm{mm}$ diameter circular aperture was employed near the detector, since collimation was found to remove a considerable amount of scatter (see fig. 9 and 10, bottom). Following is a detailed discussion of the results for the ${ }^{90 S}+90 y$ sources:

(a) Influence of Flattening Filter on ${ }^{90} \mathrm{Sr}+90 \mathrm{Y}$ Pulse-Height Distribution. Figure 10 shows that the flattening filter causes a shift in the energy endpoint. This should be kept in mind when the 2-mCi source (used with flattening filter) is replaced by the 50-mCi source (used without flattening filter) in the course of an instrument calibration.

(b) Influence of source-to-detector distance for ${ }^{90} \mathrm{Sr}+90 \mathrm{Y}$. Figure 11 shows the spectral distributions at the three distances specified by Buchler. The effect of distance is seen to be relatively small. Therefore, a change in distance, necessitated by considerations either of required absorbed-dose rate or of required size of uniform beam cross section, should not introduce an appreciable change in instrument-calibration results.

(c) Comparison of the measured pulse-height distribution with theory. For this comparison, one must consider (1) that the theoretical spectrum shown was computed for the bare $90 y$ radionuclide; and (2) that the measured spectra? distribution is for a ${ }^{90} \mathrm{Sr}+90 \mathrm{y}$ source encapsulated in $50 \mathrm{mg} / \mathrm{cm}^{2}$ of $\mathrm{silver}$ and $0.1 \mathrm{~mm}\left(77 \mathrm{my} / \mathrm{cm}^{2}\right)$ of iron, at a distance of $50 \mathrm{~cm}\left(61 \mathrm{mg} / \mathrm{cm}^{2}\right)$ in air, with a layer of about $1 \mathrm{mg} / \mathrm{cm}^{2}$ of aluminized PTP over the detector. Taking into consideration of the average and maximum beta-particle energies given in table 1 , this leads to respective approximate average and maximum ranges for 


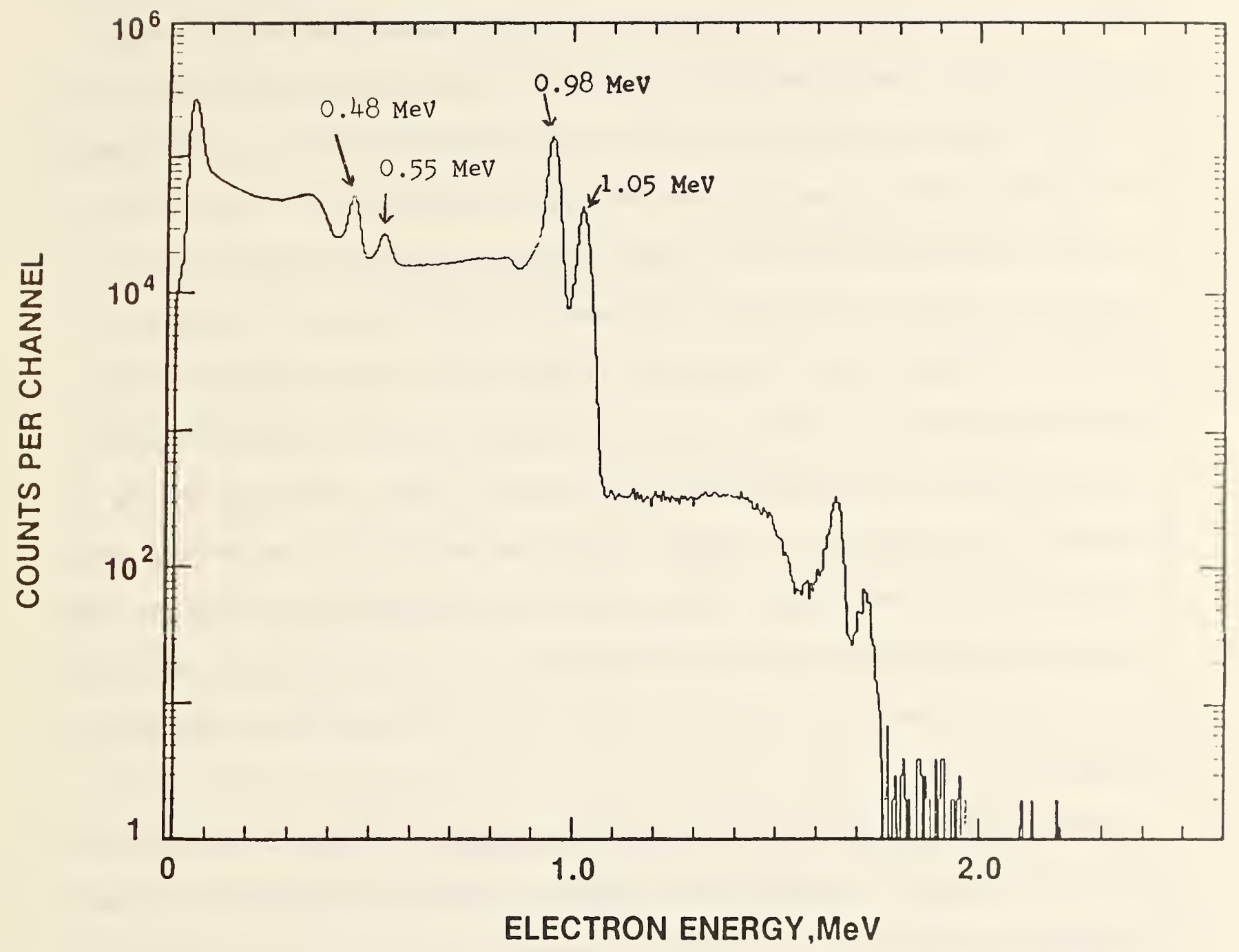

Figure 13. Energy Calibration Spectrum of 207Bi Obtained with the 5-mm Silicon Surface-Barrier Detector. Assignment of pulse-height peaks to known conversion-electron energies below $1.1 \mathrm{MeV}$ [7] took into account energy losses in the source covering, in the detector covering, and in the $2.54 \mathrm{~cm}$ of air between source and detector. 
the ${ }^{90} \mathrm{Sr}$ beta particles of 60 and $270 \mathrm{mg} / \mathrm{cm}^{2}$ in the composite total of roughly $190 \mathrm{mg} / \mathrm{cm}^{2}$ of absorber which these beta particles must traverse to reach the detector surface. As a consequence, there are relatively few ${ }^{90} \mathrm{Sr}$ beta particles reaching the detector, making the measured pulse-height distribution mainly that of $90 \mathrm{y}$, slowed down by the intervening absorbers. Figure 10 (bottom) shows that the general shape of the pulse-height distribution obtained with the collimated detector compares relatively well with the theoretical $90 y$ spectrum. The peak is roughly at the same location. The high-energy endpoint of the pulse-height distribution is at a lower energy, which is qualitatively compatible with the energy loss in the intervening absorbers. The difference in shape in the low-energy region may be the result of a composite of the residual ${ }^{90} \mathrm{Sr}$ beta particles reaching the detector (see figure 2 for the theoretical ${ }^{90} \mathrm{~S} r+90 \mathrm{Y}$ spectrum) and of the distortions introduced by detector-edge and encapsulation effects, for which no corrections were made.

(d) Change in spectrum with depth of absorber. Figure 12 shows the change of the ${ }^{90} \mathrm{Sr}+90 \mathrm{Y}$ spectrum with added thickness of polystyrene absorber, in a semi-logarithmic presentation which enhances the visibility of the effect. The results are of interest since shallow and deep absorbed-dose rates to water (or plastic) of the type shown in figure 8 often are obtained from measurements with parallel-plate ionization chambers whose response depends on spectral composition. There is seen to be a radical change in the spectrum with increasing polystyrene thickness, the thickest shown $\left(0.58 \mathrm{~g} / \mathrm{cm}^{2}\right)$ corresponding to a reduction by a factor of ten in the measured ionization current. These results emphasize the need to know the response function of the ionization chamber employed for such measurements, over a wide energy range. 


\subsection{Comparison of Different Types of $90 \mathrm{Sr}+90 \mathrm{Y}$ Sources}

Since spectral characteristics of ${ }^{90} \mathrm{Sr}+90 \mathrm{Y}$ beta-particle sources may vary widely with source yeometry, a certain degree of standardization of source construction is required if sources from different manufacturers are to be used successfully in instrument-calibration activities. ANSI N13.11 [8] specifies a filtration thick enough $\left(\sim 100 \mathrm{mg} / \mathrm{cm}^{2}\right)$ to remove the $90 \mathrm{Sr}$ component, but of a sufficiently low atomic number $(\leqslant 26)$ not to cause excessive bremsstrahlung production. The international standard, ISO 6980 [9] specifies a residual maximum energy of $\geqslant 1.80 \mathrm{MeV}$. The DOE performance-testing standard [10] will specify the limits on absorption characteristics in polymethy?methacrylate (PMMA) of the beta-particle beam emitted by the source, requiring the ratios of absorbed-dose rates to PMMA at depths of $100 \mathrm{mg} / \mathrm{cm}^{2}$ and $7 \mathrm{mg} / \mathrm{cm}^{2}$ to be equal to $1.01 \pm 0.05$, and the corresponding ratios at $1000 \mathrm{mg} / \mathrm{cm}^{2}$ and 7 $\mathrm{mg} / \mathrm{cm}^{2}$ to be less than 0.01 .

The relatively high-activity $(\sim 140 \mathrm{mCi})$ source used by the University of Michigan in the National Voluntary Laboratory Accreditation Program (NVLAP) for dosimetry performance by NRC licensees was built to the University's specifications. It is in compliance with ANSI N13.11. The source that will be used in the Department of Energy Laboratory Accreditation Program (DOELAP) for dosimetry performance by National Scientific Laboratories was manufactured by Buchler-Amersham according to specifications given by members of the National Physical Laboratory in England, who also were instrumental in developing the ISO standard.

It was considered of interest to compare the DOELAP source and the present NVLAP source by the different criteria. In this comparison, we also included an experimental source produced by Amersham to meet ANS I N13.11 specifications but designed to have less internal scattering (but much lower 
activity) than the present NVLAP source. Table 5 shows the results of this comparison. Also shown is some pertinent information on source construction. Only the experimental Amersham source is seen to meet all three criteria. The DOELAP source does not meet the ANSI criterion since it contains silver. The NVLAP source does not meet the ISO criterion.

Further elucidation of these results is possible if one examines the response-versus-depth curves on which the DOELAP criterion is based (fig. 14) and the associated pulse-height distributions (figs. 15 through 19) which give equivalent information but can be obtained with less effort than attenuation curves. They show that the experimental Amersham source indeed has the most energetic spectrum and that the present NVLAP source is degraded most. They also reveal certain critical information about the selection of criteria for source specification: They reveal that an operational criterion of the DOELAP or ISO type may be better suited for obtaining desirable source characteristics than a criterion of the ANSI N13.11 type which specifies material properties and dimensions. They also reveal that the DOELAP criterion is too loose, since it does not discriminate between the operationally very different NVLAP and Amersham experimental sources, while the ISO criterion does. The high (only slowly decaying) background noise shown in figure 14 for results obtained after irradiation of the extrapolation chamber with a high-intensity electron beam alerts one to the need for special care in the use of such a chamber.

3. The NBS Close-to-Monoenergetic Electron Calibration Facility [11]

The NBS 500-keV cascade-rectifier accelerator and 4-MeV Van de Graaff accelerators were adapted for application in the calibration of radiationprotection instruments by (a) magnetic scanning of the electron beams in a two-dimensional raster pattern in order to produce suitably large beam cross 


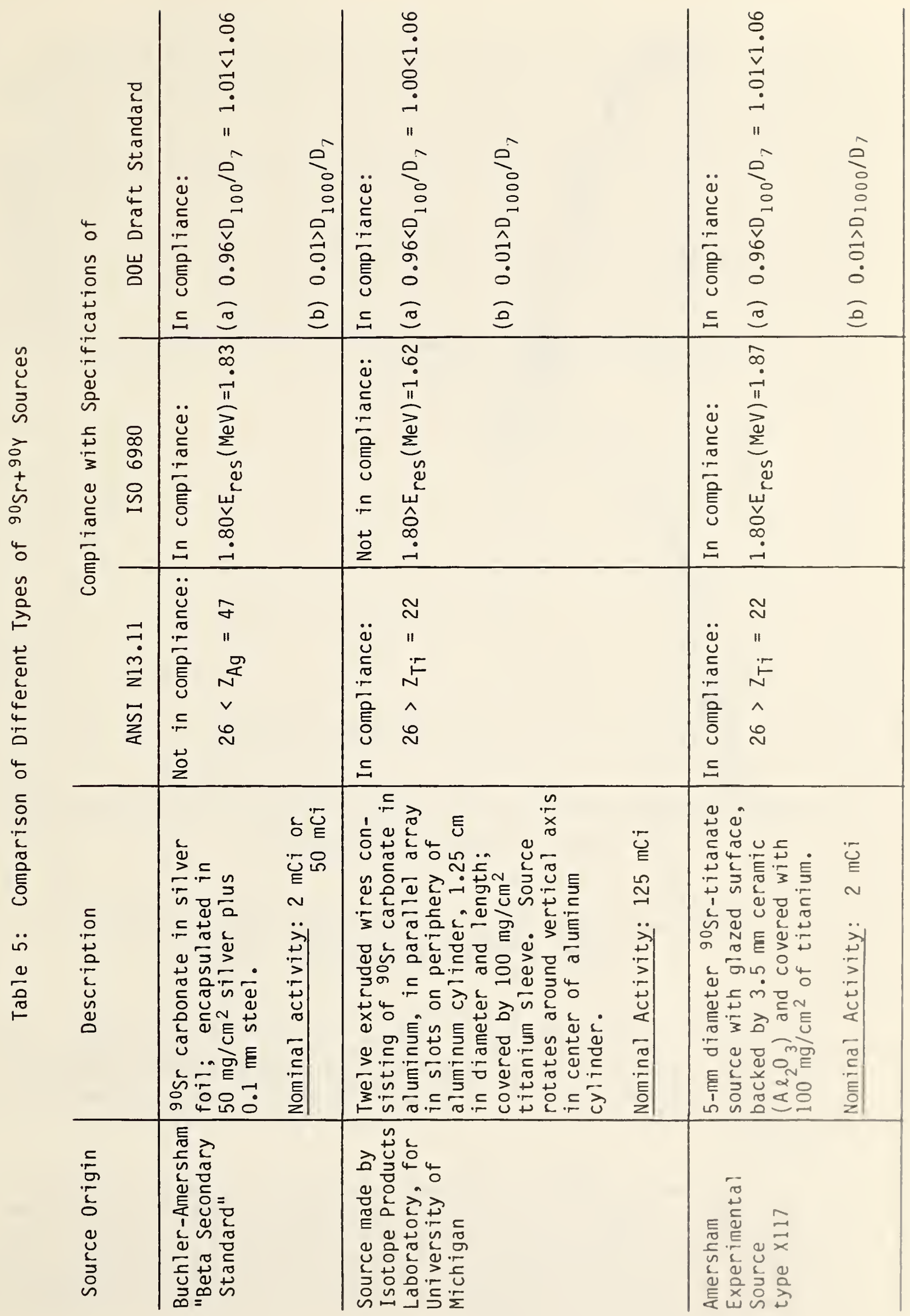




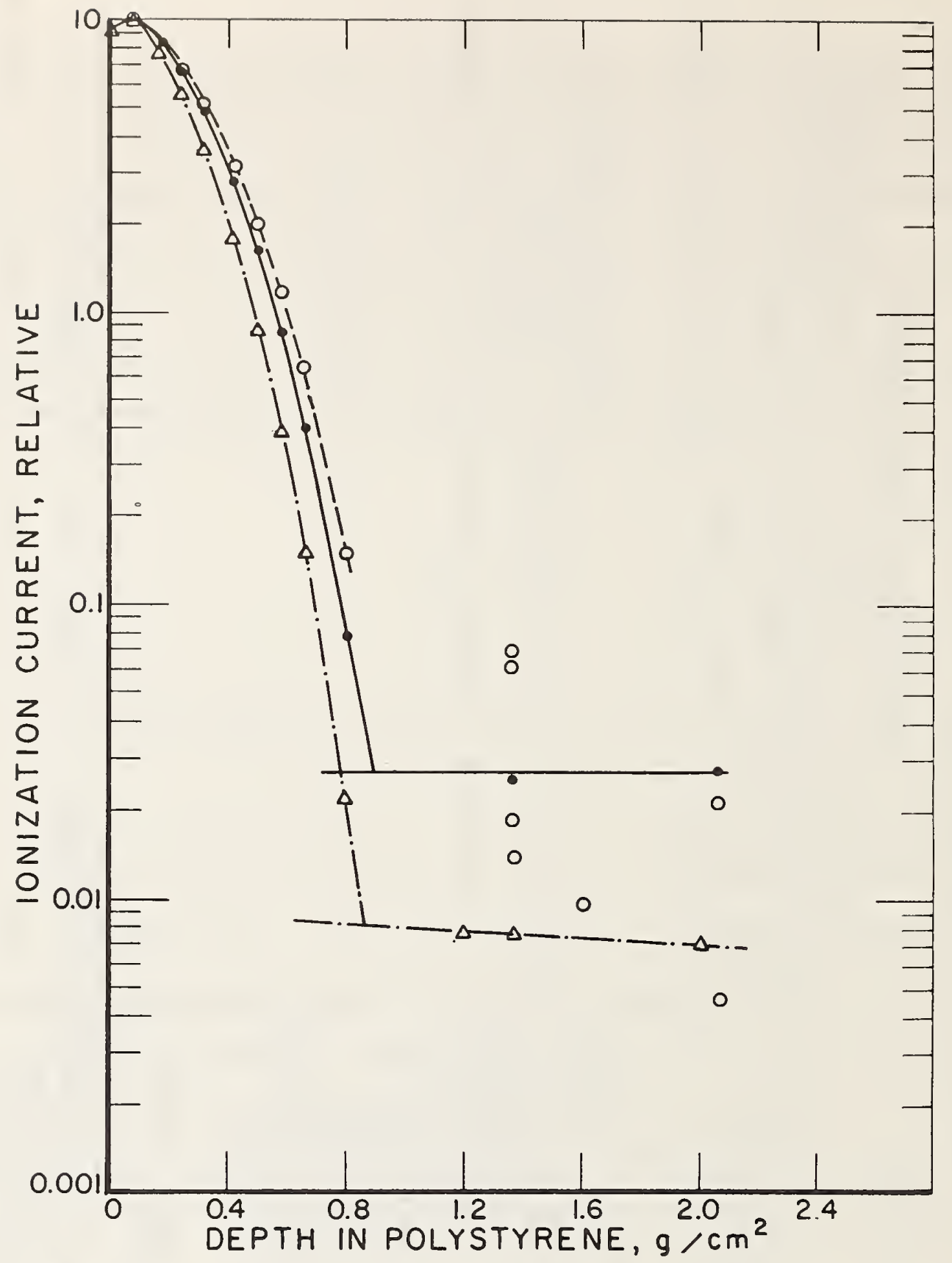

Figure 14. Ionization-versus-Depth Curves for Three Different types of ${ }_{90}$ Sr+90y Sources. Solid line: Buchler-Amersham source; dashed line: Amersham experimental source; dash-dotted line: special high-activity NVLAP source.

The curves in PMMA are undistinguishable from those in polystyrene. No line could be drawn for the bremsstrahlung background of the Amersham experimental source because of the wide scatter of the associated data points (some of them off-scale, representing relative ionization currents $<0.001)$. This behavior probably was due to the erratic high background noise introduced in the ionization chamber by a preceding irradiation in a high-intensity electron beam. 


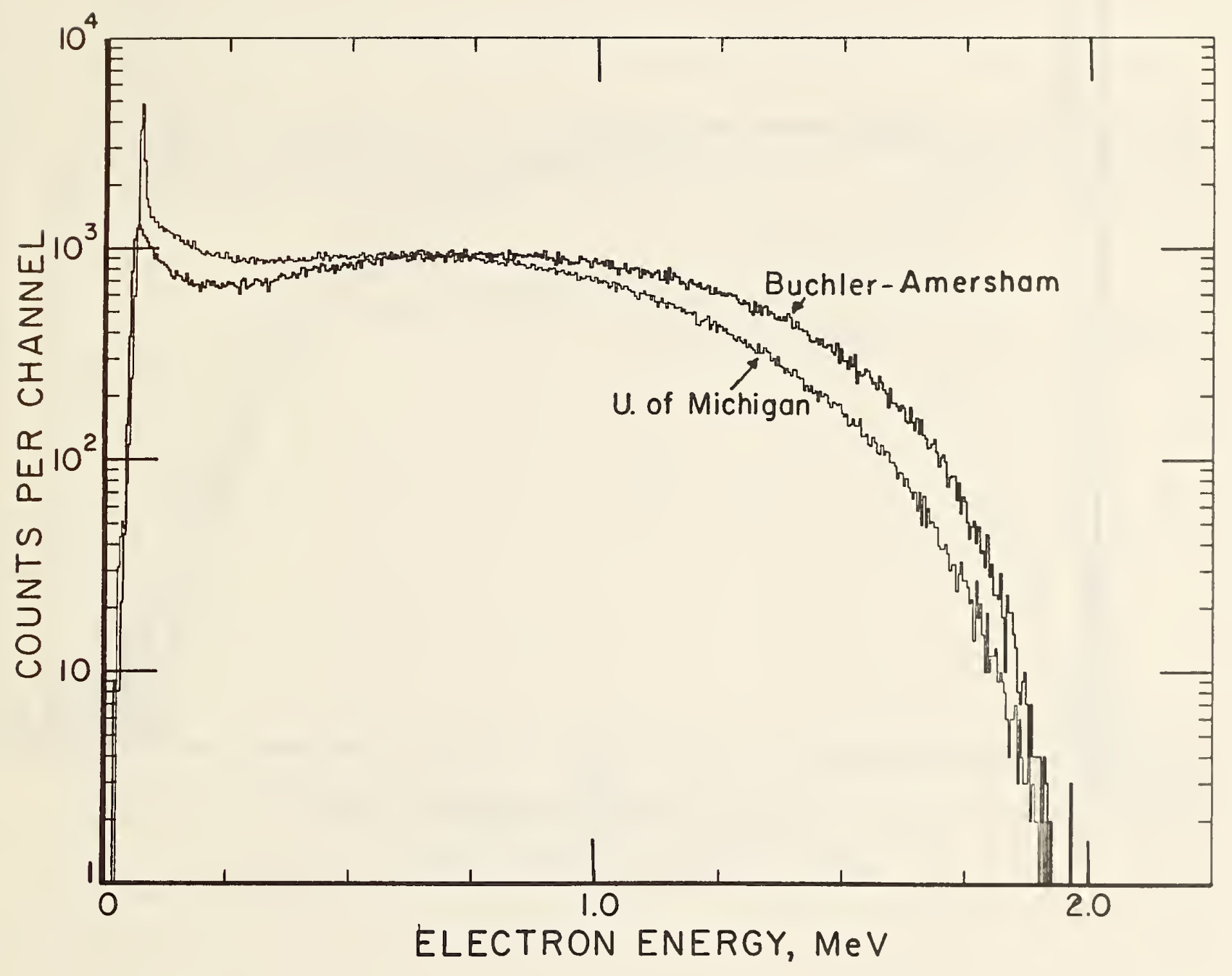

Figure 15. Comparison of Spectrum of Buchler-Amersham and University of Michigan (NVLAP) ${ }^{90} \mathrm{Sr}+90 \mathrm{Y}$ Sources, on Semi-Logarithmic Scale. The ordinates were adjusted for equal total number of counts. 


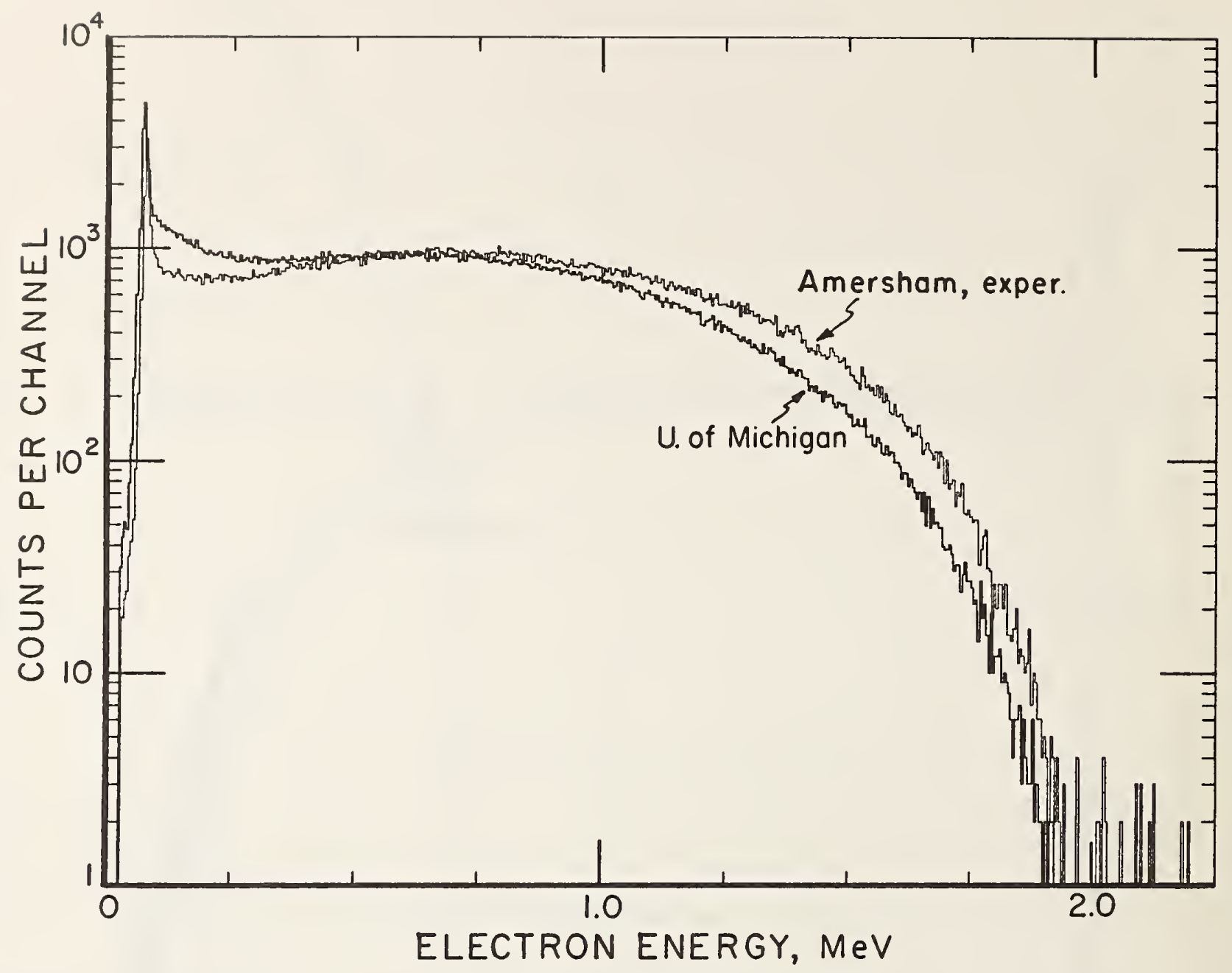

Figure 16. Comparison of Spectrum of Amersham Experimental and University of Michigan (NVLAP) ${ }^{9} .0 \mathrm{Sr}+90 \mathrm{Y}$ Sources, on Semi-Logarithmic Scale. The ordinates were adjusted for equal total number of counts. 


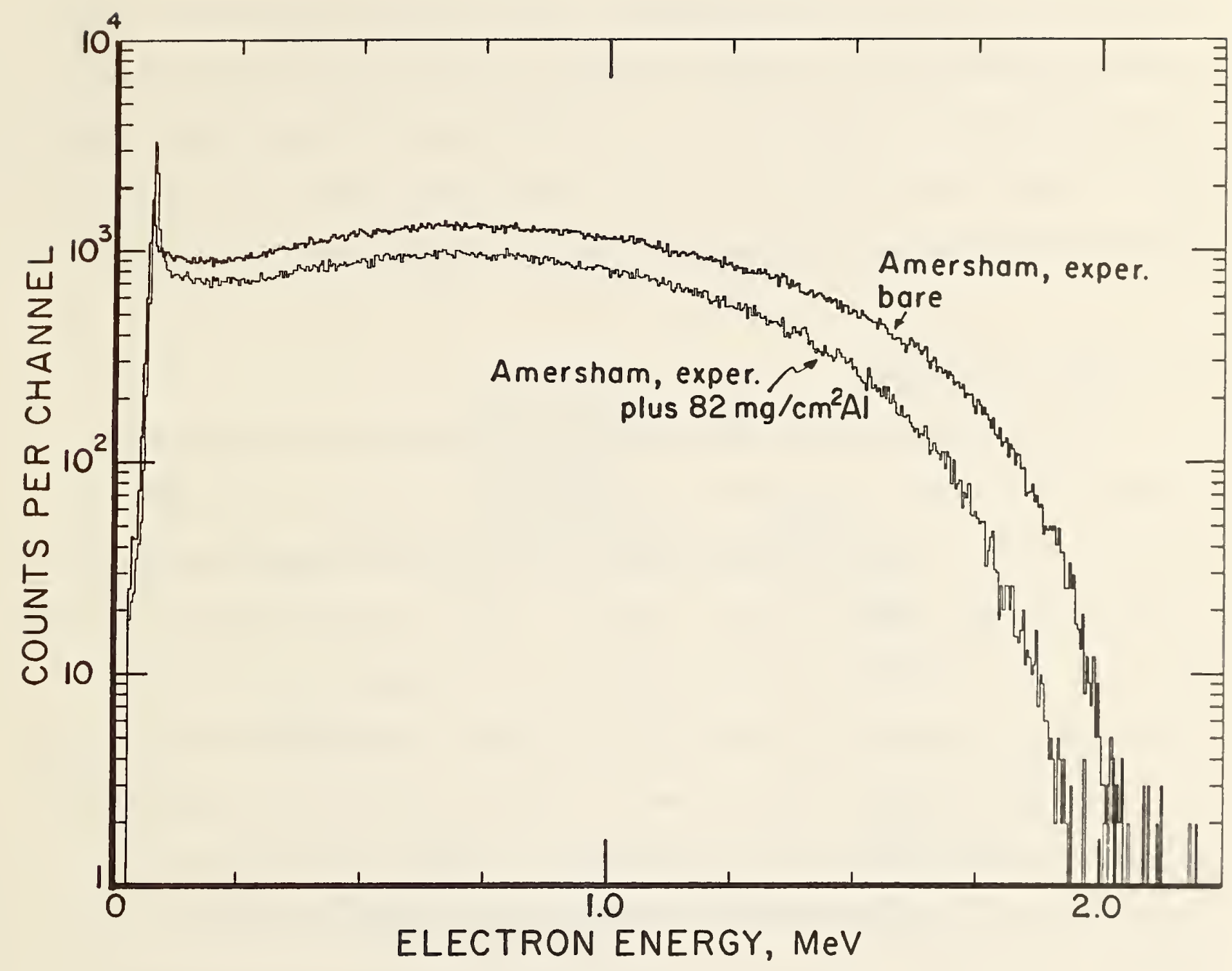

Figure 17. Difference between Buchler-Amersham and Amersham Experimental ${ }^{90} \mathrm{Sr}+90 \mathrm{y}$ Sources, on Semi-Logarithmic Scale. Adding $82 \mathrm{mg} / \mathrm{cm}^{2}$ of aluminum to the Amersham experimental source is seen to make its spectrum similar to that of the Buchler-Amersham source (fig. 15). 
sections; and (b) having the beams exit from the vacuum through thin, low- $z$ windows and keeping the air paths as short as possible in order to prevent unnecessary spectral degradation. In the following, the experimental setup and the beam characterization in terms of beam cross section and uniformity, electron spectrum, and absorbed-dose rates to plastic will be discussed.

\subsection{Experimental Setup}

The beam håndling arrangement is shown schematically in figure 18 . Aligned and focused electron beams of energies from $200 \mathrm{keV}$ to $2.5 \mathrm{MeV}$ are passed through a set of deflection coils which cause the beam to be scanned in a two-dimensional raster pattern. The scan signal has a horizontal frequency of $416 \mathrm{~Hz}$ and a vertical frequency of $12.5 \mathrm{~Hz}$; the amplitudes in the two directions are independently variable. The exit windows must be thick enough to withstand atmospheric pressure over a large area, yet thin enough not to degrade the electron beam energy appreciably. A thin foil (25 $\mu \mathrm{m})$ of commercially available polyimide is well-suited for electron energies up to $500 \mathrm{keV}$. At higher energies, for which energy degradation does not pose a large problem, either the same type of foil or a $0.10-\mathrm{mm}$ aluminum foil is used.

The electron beam position is checked frequently, especially at the lower energies. This is done by viewing the beam remotely on a light-emitting phosphor screen placed at the exit window. The unscanned beam is centered on the exit window and the scanning-signal amplitudes are adjusted to spread the scanned beam over the window area. At both accelerators, beam intensity is continuously monitored with a fast plastic scintillator-photomultiplier detector placed in an off axis location $\left(60^{\circ}\right.$ off-axis and $20 \mathrm{~cm}$ from the exit window at the low-energy accelerator, and $30^{\circ}$ off-axis and $40 \mathrm{~cm}$ from the exit 


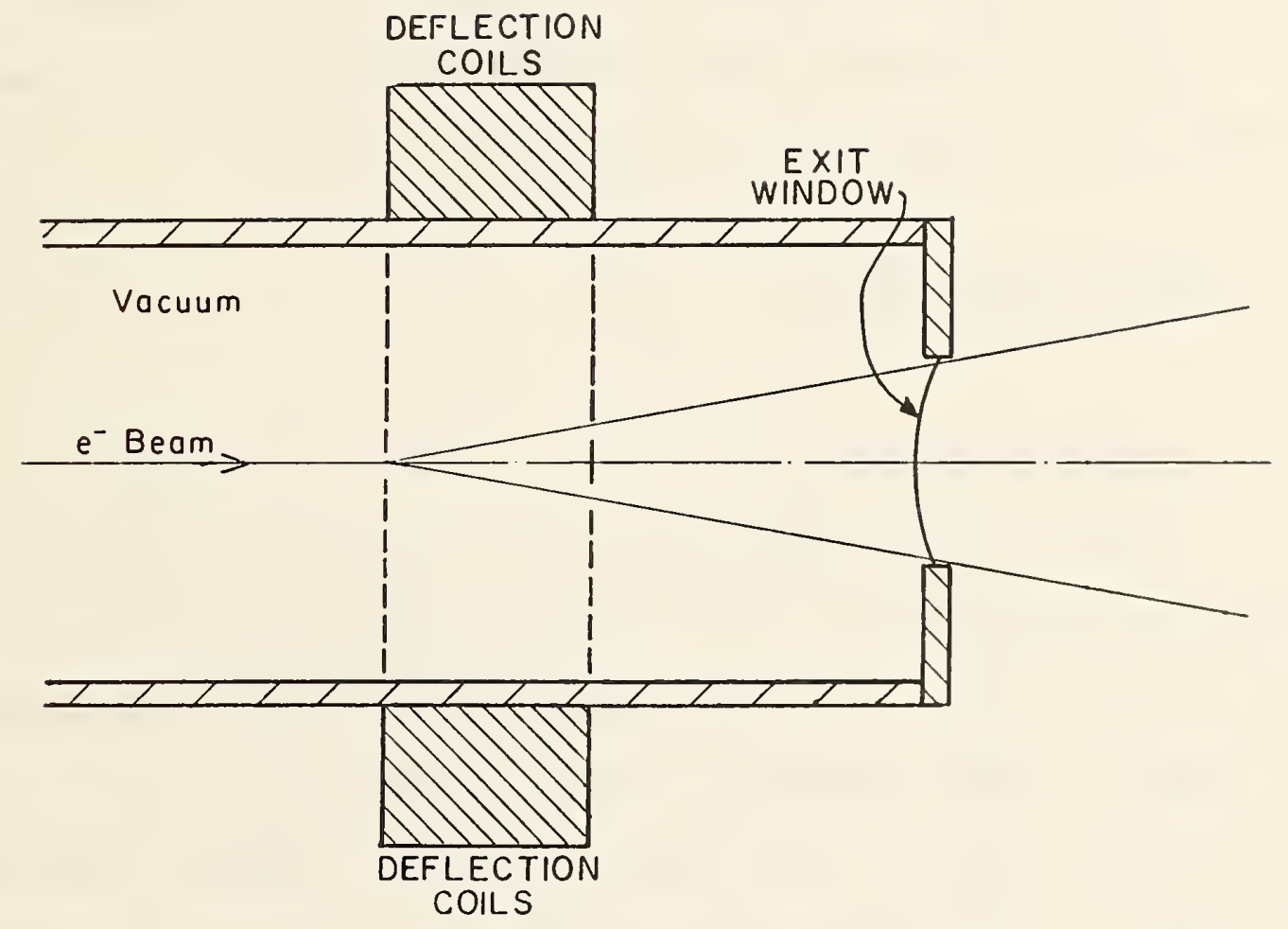

Figure 18. Beam-Handling Arrangement. 
window at the Van de Graaff accelerator). In order to limit counting rates, the monitor is equipped with a collimator with a circular aperture, $2 \mathrm{~mm}$ in diameter, located near the front surface of the scintillator. The fast (10-ns wide) pulses from the detector allow counting rates up to $10^{5} \mathrm{~s}^{-1}$ with no significant pile-up and with very low background rates $\left(<2 s^{-1}\right)$. Because of fluctuations in beam position (beam "wandering") which limits dosimetry reproducibility, plans for the future include the installation of a circular array of four or more fast plastic scintillator-photomultiplier monitors, eventually to be coupled with the beam-steering system.

\subsection{Beam Characterization}

\subsubsection{Beam Cross Section}

The degree of uniformity of the electron-beam cross section was determined radiographically over a range of electron energies and distances from the exit window. Industrial x-ray film was used, in light-opaque paper envelopes for electron energies of $300 \mathrm{keV}$ and above and bare in a darkened room for lower energies. Densitometric scans were obtained of the optical densities of the radiographs along two perpendicular diameters of the essentially circular inages of the beam cross sections. Figure 19 shows plots of the Gaussian fits to representative data obtained for several electron energies from $200 \mathrm{keV}$ to $2.5 \mathrm{MeV}$ at several distances from the exit window. Plots of this type permit a choice of distance from the exit window suitable for covering an instrument of a given size with a beam of a cross section of a pre-determined degree of uniformity. A synposis of the results is shown in the first three columns of table 6 where usable field size is shown over the covered energy range. 

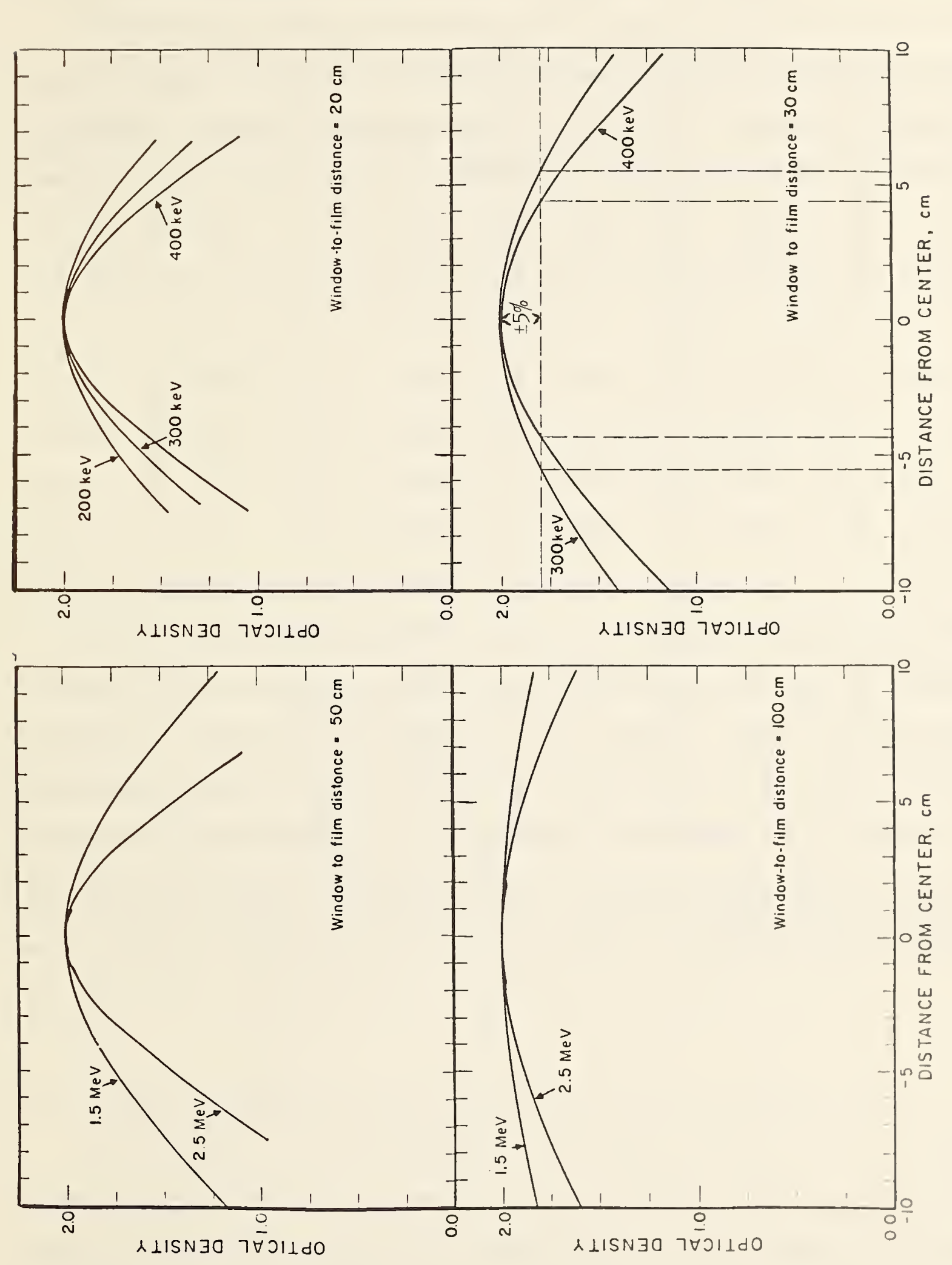

운

ธ。

\&)

万ั

욤

แิ?

$\leftarrow$ Ч ํํ

岌

ฮั ญ

$\simeq \frac{5}{4}$

岳芒

c

누원

- 들을

ह

ญ르

- ए थ

ธᄂ ข

$+\frac{1}{3}$

\& 0 음

용ㄹㅇ

E

ฮู

U

$4 \frac{1}{0}$ 제

든 논

uㄷ

虫

$\sim \tilde{\alpha} \leftarrow$

$\approx$ Е

는

+ प $\frac{5}{3}$

$\circ$ 在

त)

Eथ

등 긴

- in

둥

4 थे

० เ. -

\&

ह. - E

อั แ้ 
Table 6. Pertinent Electron Beam Parameters

\begin{tabular}{c|c|c|c|c|c}
\hline \hline $\begin{array}{c}\text { Accelerator } \\
\text { Potential }\end{array}$ & $\begin{array}{c}\text { Distance } \\
\text { From Window }\end{array}$ & $\begin{array}{c}\text { Usable } \\
\text { Field Size }\end{array}$ & $\begin{array}{c}\text { Most Probable } \\
\text { Electron Energy }\end{array}$ & $\begin{array}{c}\text { Minimum } \\
\text { Dose Leve }\end{array}$ & $\begin{array}{c}\text { Maximum } \\
\text { Dose Rate }\end{array}$ \\
\hline (kV) & $(\mathrm{cm})$ & $(\mathrm{cm})$ & $(\mathrm{keV})$ & $(\mu \mathrm{Gy})$ & (mGy s-1) \\
200 & 20 & 8.3 & 130 & 140 & 70 \\
300 & 30 & 11 & 220 & 30 & 15 \\
300 & 20 & 6.7 & 250 & 70 & 35 \\
400 & 30 & 8.7 & 340 & 90 & 45 \\
400 & 20 & 5.7 & 360 & 190 & 95 \\
1500 & 100 & 22 & 1280 & 13 & 7 \\
1500 & 50 & 8.9 & 1370 & 90 & 45 \\
2500 & 100 & 14 & 2230 & 60 & 30 \\
2500 & 50 & 5.7 & 2320 & 350 & 175 \\
\hline
\end{tabular}

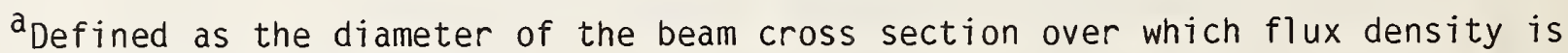
uniform to within $\pm 5 \%$. 


\subsubsection{Beam Dosimetry}

The method for determining absorbed-dose rates to plastic at the reference point was similar to that used with the beta-particle sources except that a correlation had to be established between the signal from the extrapolation chamber at the reference point (referred to reference temperature and pressure) and the signal from the fast plastic scintillator used to monitor the fluctuating beam. Measurements of the ratio of absorbed-dose rate to monitorcounting rate were made for each of the chosen accelerator potentials and exit window-to-detector distances. The second-to-last column of table 6 represents the dose obtained in 10 seconds at a nominal monitor counting rate of 20 per second, which is the minimum rate that can be monitored with a sufficient degree of accuracy. The maximum dose rates shown in the last column of the table correspond to a monitor counting rate of $10^{5}$ per second.

The ratio of absorbed-dose rate to monitor counting rate was reproducible to within about \pm 1 percent unless either the machine was turned off between measurements or the accelerator potential was changed. These procedures caused changes of \pm 10 percent in the ratio, although no beam shift was detectable by direct viewing of the beam spot. Therefore, until a more effective beam control is installed, it will be necessary to establish the ratio of the absorbed-dose rate at the reference point to the monitor counting rate before and after each run at a particular accelerator potential.

\subsubsection{Spectral Composition of the Electron Beam at the Reference Point}

The 5-mm deep silicon surface-barrier detector equipped with the 1.6-mm aperture lead collimator (see section 2.3) was employed. Beam currents were limited so that count rates did not exceed $2000 \mathrm{~s}^{-1}$. Measurement procedures 
were similar to those employed for beta-particle spectrometry. Therefore, the same caveats expressed in 2.3 about absolute spectral shapes apply here, as we]1. The importance of making the exit windows (polyimide for the low energies, aluminum for the high energies) as thin as possible is brought out in figures 20 and 21 . Figure 22 shows the spectral distributions as a function of the distance between detector and exit window. At low electron energies, degradation in air is seen to be not negligible, but the spectra are still fairly narrow at distances at which the beam cross section is sufficiently large and uniform for the study of survey instruments. The most probable energies shown in these figures were used in column 4 of table 6 , relating these energies to accelerator potential, exit window-to-detector distance, and usable field size.

4. Prediction of Instrument Response to Beta Particles from Response to Close-to-Monoenergetic Electrons

In order to assess the practical value of a study of radiation-protection instruments in close-to-monoenergetic electron beams, knowledge is required of how well one can predict instrument response in realistic beta-particle fields from their response to monoenergetic electrons. (Note that the term "response" is used here to signify instrument-scale indication per unit of absorbed dose to water or plastic.) In principle, this prediction is straightforward, involving the folding of the beta-particle spectrum of interest into the instrument response to monoenergetic electrons (i.e., into the instrument's "response function"), over the energy range covered by the beta-particle spectrum. In practice, both the spectrum and the response function may not be known in great detail and with great accuracy. The question then arises what level of detail and accuracy in the knowledge of the beta-particle spectrum and the instrument's response function to monoenergetic 


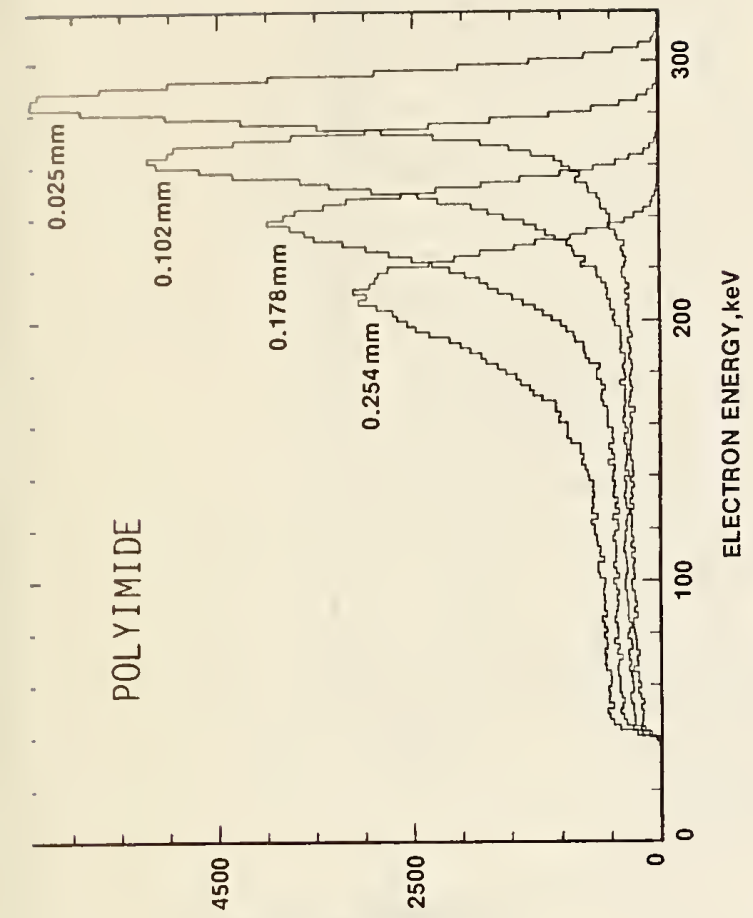

ר $\exists$ NN $\forall$ HO Hヨd SINกOO
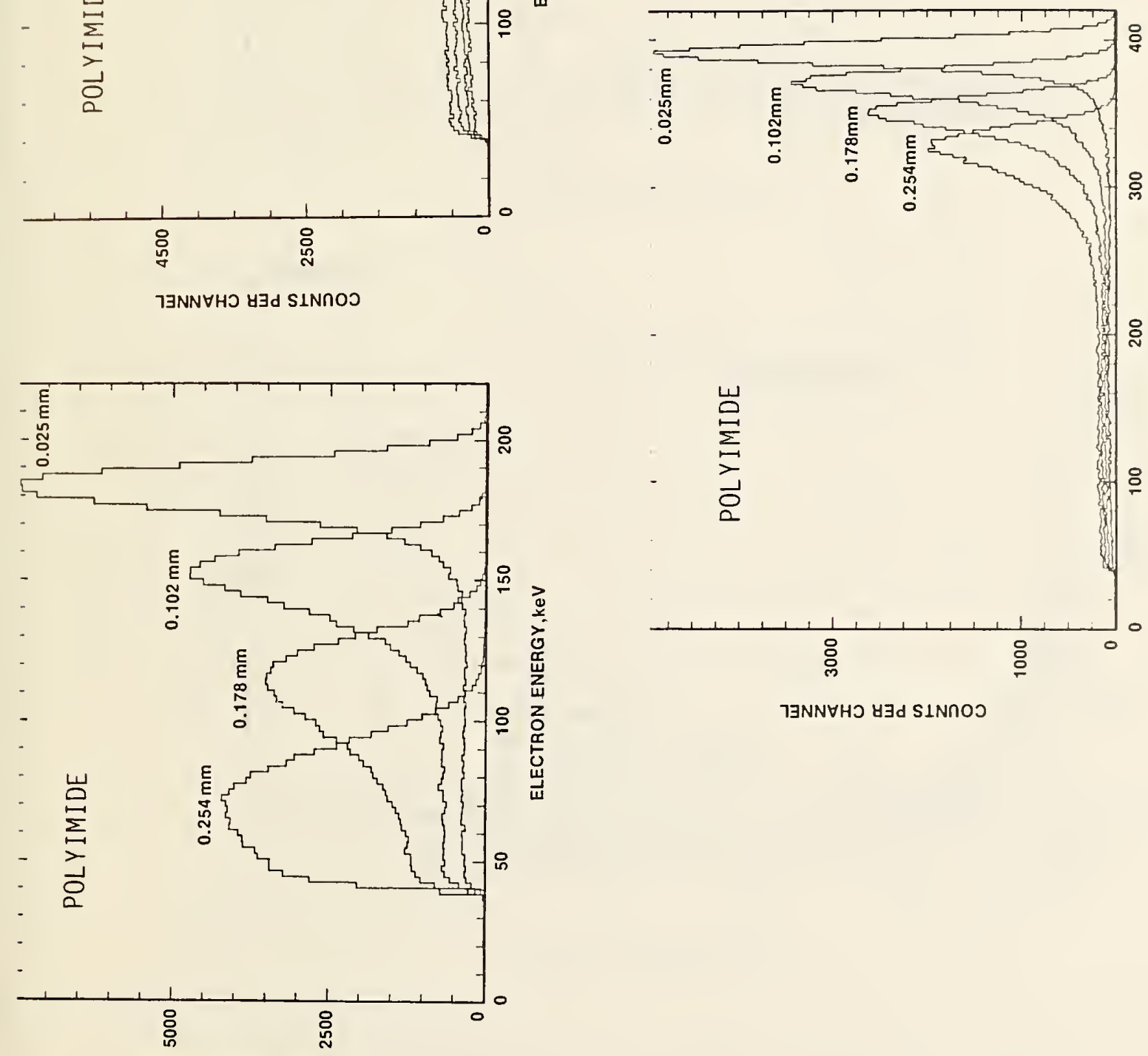

$\div$

范

« ำ

a

造 3

u

E. ำ

$\stackrel{\square}{\rightleftarrows}$

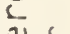

选 万

4

0 บ

$=\frac{1}{0}$

^

ษับ

Ш ه

¿

눈

8.

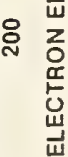

을

य)

仓․․

$>$ ป

$\because E$

82

잉

$\overrightarrow{0} \equiv$

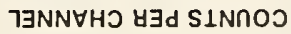

怘

E nी

은

$<0$

尔 0

5 간

을

-

0

20 0

금

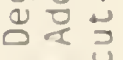

: 2

NE

Q $>2$

중 

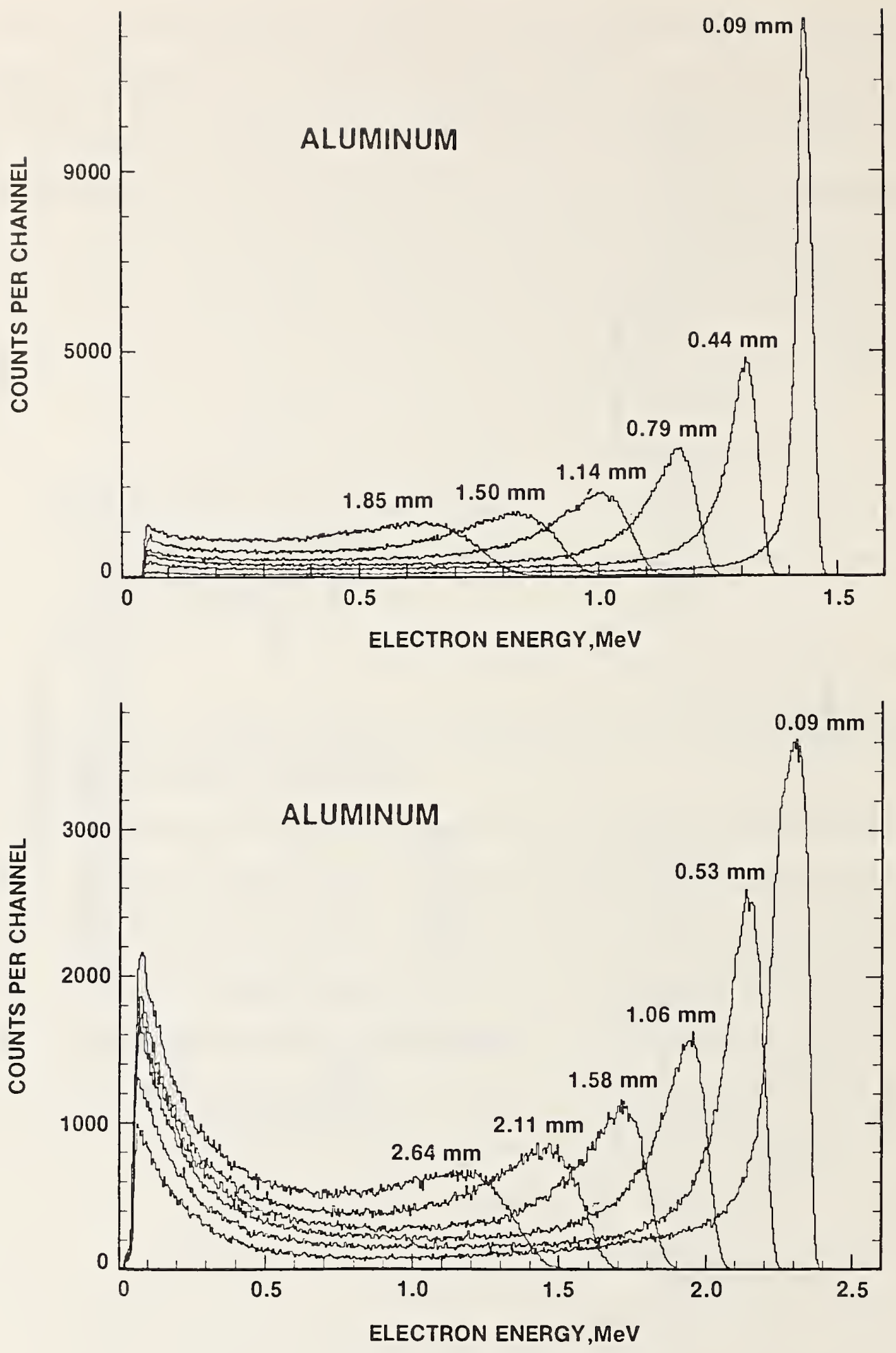

Figure 21. Degradation of Nominal 1.5-MeV and 2.5-MeV Electrons in Different Thicknesses of Aluminum Added to the 0.09-mm Aluminum Exit Window. Distance between detector and exit window: $2.0 \mathrm{~cm}$ for $1.5 \mathrm{MeV}$ electrons, $50 \mathrm{~cm}$ for 2.5-MeV electrons. 

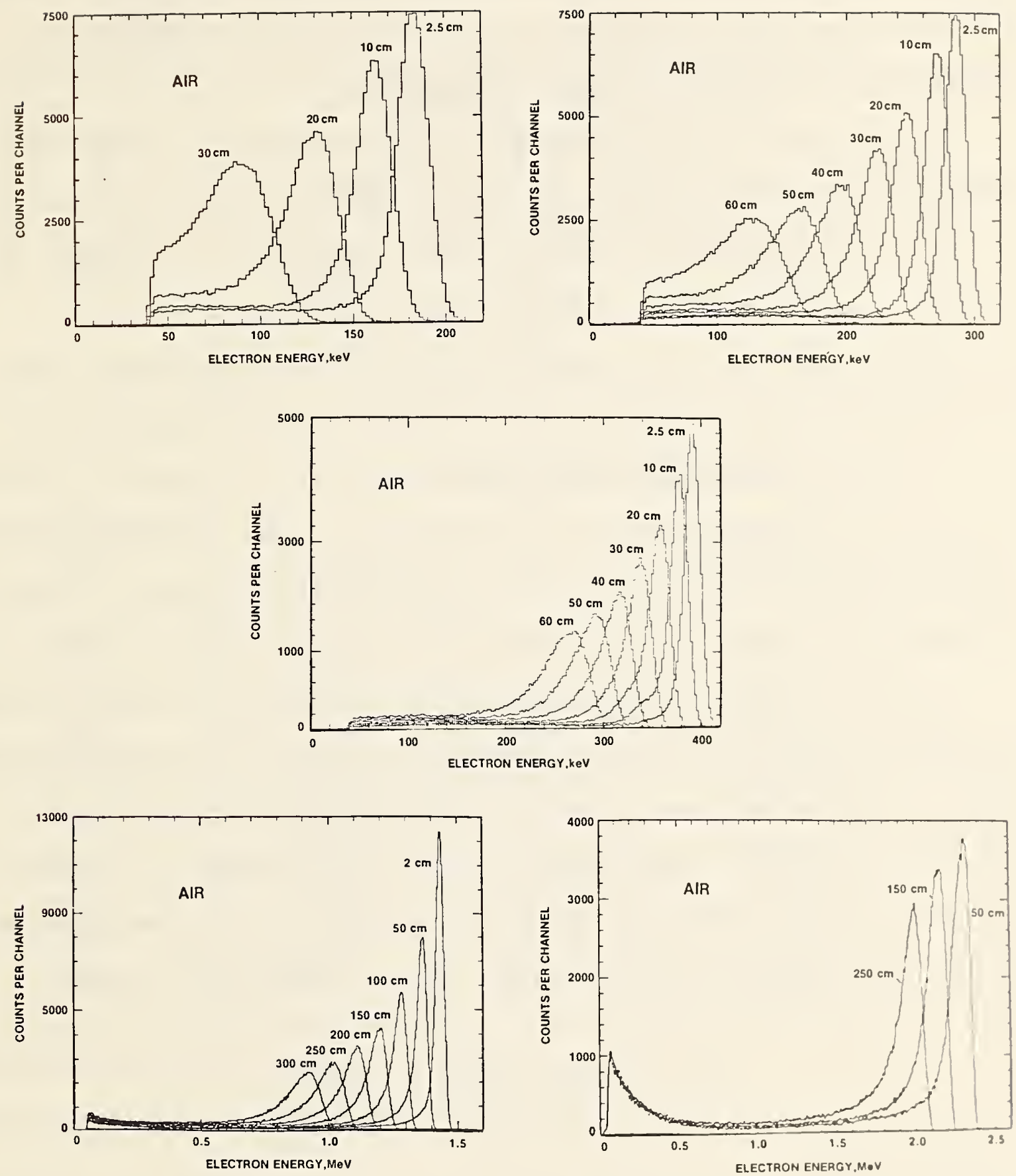

Figure 22. Degradation in Air of Nominal 200-keV to 2.5-MeV Electrons in Different Thicknesses of Intervening Air Layers. 
electrons are sufficient to compute instrument response to practical betaparticle fields within acceptable limits of uncertainty. Following is a report on a first attempt to answer this question.

In the course of a related NRC project, the response of a number of radiation-protection instruments was studied both in the beta-particle beams and the close-to-monoenergetic electron beams. Among these instruments was a thermoluminescence personnel dosimeter (TLD); a survey meter of the ionization-chamber type with a promising response to beta particles; and a silicon surface-barrier detector used to simulate the sensitive element of state-of-the-art survey-meter/spectrometers, which rely on internal algorithins for obtaining absorbed-dose rates in the materia? of interest from measured pulse-height distributions. Preliminary response characteristics for these instruments are shown in table 7 at a number of discrete electron energies.

In order to simplify the folding procedure, an attempt was made to obtain approximate response functions in closed form by fitting the response data of table 7 to simple functions. Figures 23 through 25 show the results. Two functions were used for one of the instruments which exhibits a pronounced low-energy cut-off. Response, $R_{\beta}$, to the radiation fields of the three betaparticle sources at the reference points then was computed by forming:

$$
R_{\beta}=\sum_{i} r_{j}\left(\bar{T}_{i}\right) n_{j}^{\beta}\left(\vec{T}_{i}\right) / \sum_{i} n_{j}^{\beta}\left(\bar{T}_{j}\right),
$$

where $r_{j}\left(\bar{T}_{j}\right)$ is the response of the particular instrument to close-to-monoenergetic electrons of average energy $\bar{T}_{i}$ in the ith electron energy interval, and $n_{j}^{\beta}\left(\bar{T}_{j}\right)$ is the number of beta particles of average energy $\bar{T}_{j}$ in this interval (see figs. 9-11). Table 8 shows the results of this computation for 
Table 7. Response Characteristics Measured for Three Types of Beta-Particle Detectors

\begin{tabular}{c|c|c|c}
\hline \multirow{2}{*}{ Radionuclide } & \multicolumn{2}{|c}{ Response to Beta Particles } \\
& Ion Chamber & TLD $^{\mathrm{D}}$ & Si Surface-Barrier Detector \\
\hline $147 \mathrm{Pm}$ & 0.05 & 0.00 & 0.12 \\
$204 \mathrm{Tl}$ & 0.31 & 0.82 & 0.33 \\
$90 Y$ & 0.70 & 1.70 & 1.08 \\
\hline
\end{tabular}

\begin{tabular}{c|c|c|c}
\multirow{2}{*}{$\begin{array}{c}\text { Electron Energy } \\
(\mathrm{keV})\end{array}$} & \multicolumn{2}{|c}{ Response to Monoenergetic Electrons } \\
\hline 130 & Ion Chamber & TLD $^{\mathrm{b}}$ & Si Surface Barrier Detector \\
220 & 0.24 & 0.01 & 0.17 \\
250 & 0.31 & 0.91 & 0.40 \\
340 & 0.34 & 1.16 & 0.54 \\
360 & 0.43 & 0.98 & 0.60 \\
1280 & 0.38 & 1.05 & 0.58 \\
1370 & 1.59 & 3.37 & 0.98 \\
2230 & 1.61 & 4.23 & 1.24 \\
2320 & 1.19 & -- & 2.15 \\
\hline
\end{tabular}

${ }^{a}$ Expressed relative to response to $\mathrm{Cs}-137$ photons.

${ }^{b}$ Expressed relative to response to Co-60 photons.

${ }^{C}$ Response here was calculated as a quantity proportional to the mean stopping power of water: $\sum_{i} n_{i}\left(\bar{T}_{i}\right) s_{H_{2} 0}\left(\bar{T}_{i}\right) / \sum_{i} n_{i}\left(\bar{T}_{i}\right)$, where $n_{i}\left(\bar{T}_{i}\right)$ is the number of pulses in the ith pulse-height interval corresponding to an average electron energy $\bar{T}_{i}$, and $\mathrm{s}_{\mathrm{H}_{2} 0}\left(\overline{\mathrm{T}}_{i}\right)$ is the stopping power in water in this interval, restricted to electron energies $\geqslant 10 \mathrm{keV}$ [12]. The 10-keV cutoff corresponds to the lowest pulse-height measured with the silicon surface-barrier detector. 


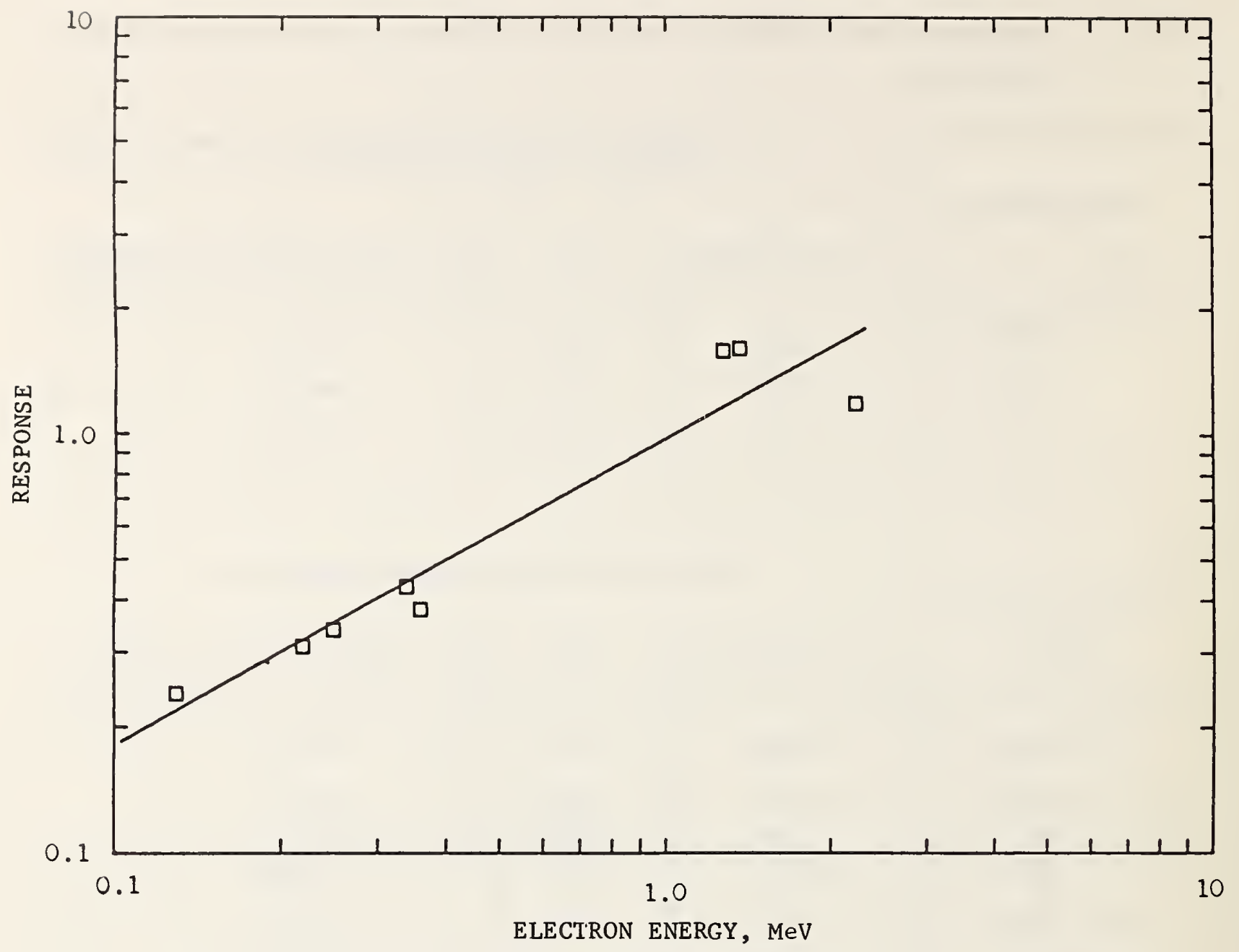

Figure 23. Response Function of Ionization-Chamber Type Survey Meter to Monoenergetic Electrons Relative to Response to Cs-137 Gamma Radiation. 


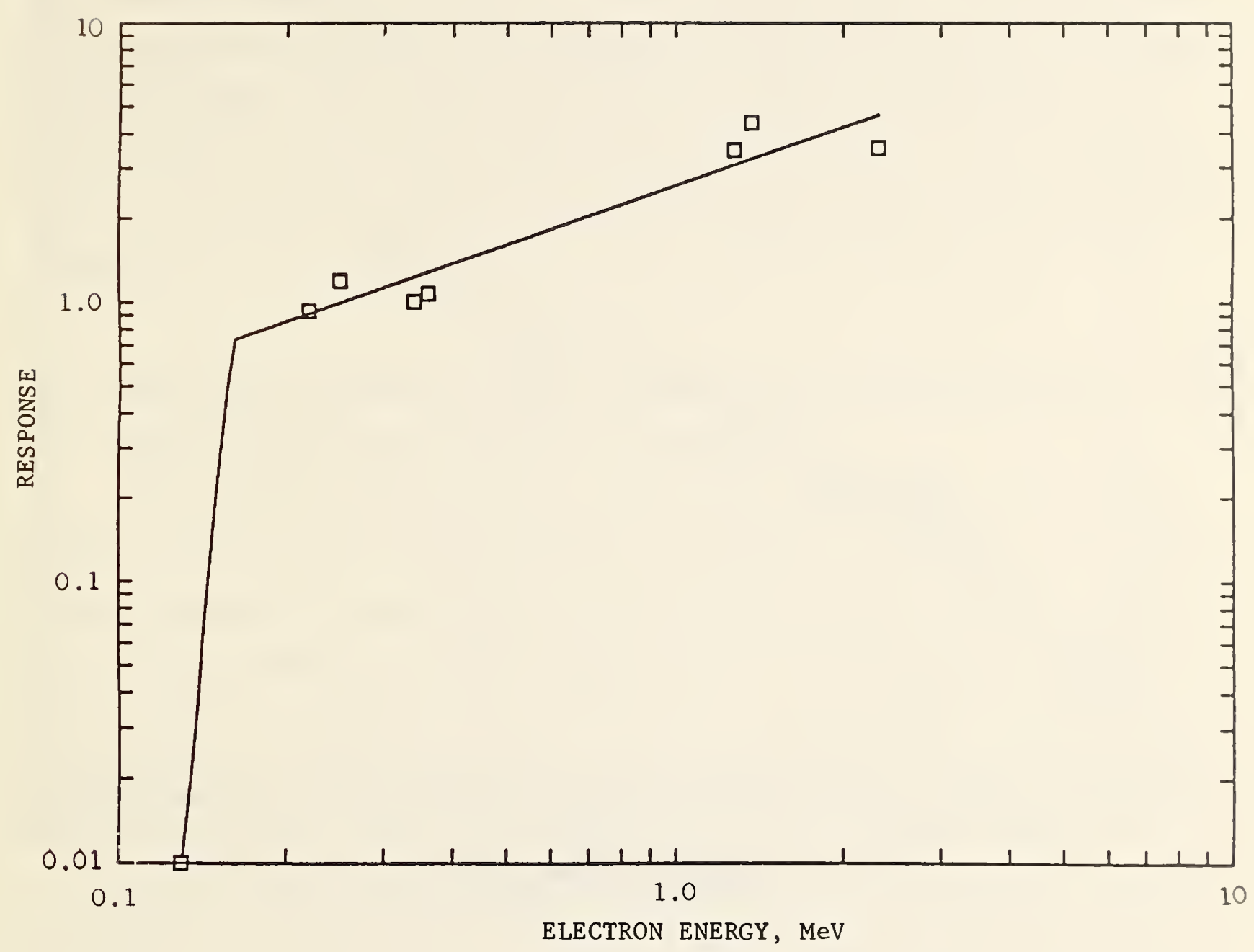

Figure 24. Response of Thermoluminescence-Type Personnel Dosimeter to Monoenergetic Electrons Relative to Response to Co-60 Gamma Radiation. 


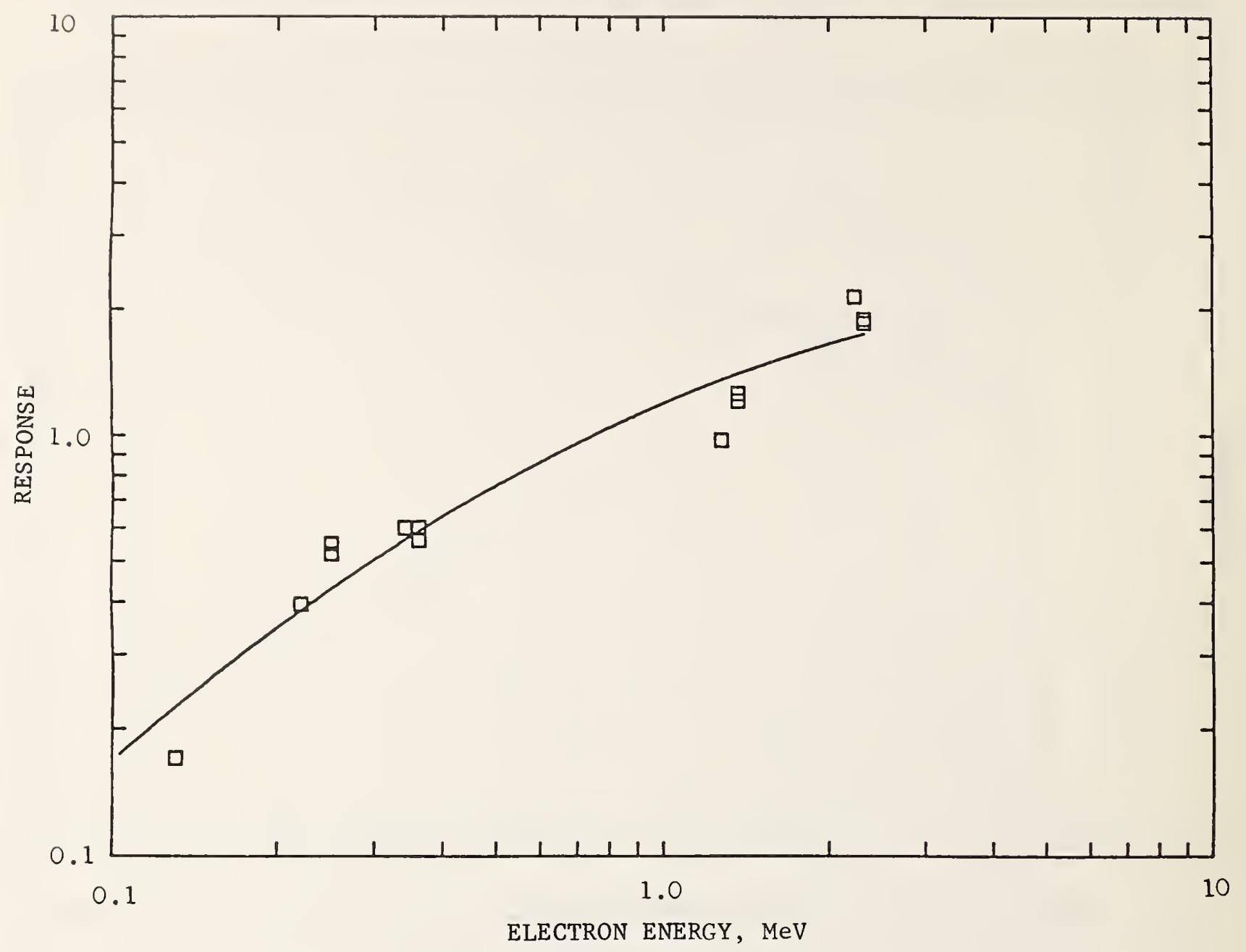

Figure 25. Response of Silicon Surface-Barrier Detector to Monoenergetic Electrons Relative to Beam-Monitor Signal. 
the three instruments and the three types of beta-particle sources, along with the measured responses from table 7. The results are fair. It is felt that improvements can be achieved (a) by obtaining definitive values for instrument response, which - among other things - would require an improvement in electron-beam control; (b) by refining the functional fits or by working with point-by-point interpolations; and (c) by fully correcting the beta-particle spectra.

5. Guidelines for Establishing Secondary Calibration Laboratories for Radiation-Protection Sources and Instruments

During the past several years, efforts have been made to find a professional society or some other independent organization interested in improving radiation-protection measurements and instrumentation, and willing to sponsor one or more secondary calibration laboratories. These laboratories would assist NBS in disseminating the pertinent national measurement standards and in improving the understanding among user yroups of how to select and employ radiation-protection sources and instrumentation with adequate results.

It was envisaged that the sponsoring organization would require a set of guidelines for the physical facilities and criteria for the operation of a secondary calibration laboratory under its sponsorship, and that such guidelines probably would be developed by a consensus among the sponsoring organization, NBS, and other interested Government agencies and user groups. Therefore, the NRC requested that NBS develop draft guidelines that could function as a basis for further discussions once the sponsoring agency was found. Appended to this report are (a) proposed guidelines for establishing secondary calibration laboratories equipped with standardized beta particle, and neutron sources, 3 and with the facilities and know-how for studying the response of

${ }^{3}$ Guidelines covering photon sources are being developed by NBS in cooperation with the Conference of Radiation Control Proyram Directors. 
Table 8. Comparison of Directly Measured and Calculated Instrument Response to Beta-Particle Spectra

\begin{tabular}{|c|c|c|c|c|c|c|}
\hline \multirow{3}{*}{ Radionuclide } & \multicolumn{6}{|c|}{ Response to Beta Particles } \\
\hline & \multicolumn{2}{|c|}{ Ion Chamber ${ }^{a}$} & \multicolumn{2}{|c|}{ TLD $^{b}$} & \multicolumn{2}{|c|}{ Si-Surface-Barrier Detector ${ }^{C}$} \\
\hline & Meas. & Calc. & Meas. & Calc. & Meas. & Calc. \\
\hline $147 \mathrm{Pm}$ & 0.05 & 0.13 & 0.00 & 0.01 & 0.12 & 0.10 \\
\hline $20^{4} \mathrm{Tl}$ & 0.31 & 0.34 & 0.82 & 0.78 & 0.33 & 0.40 \\
\hline $90 y$ & 0.70 & 0.77 & 1.70 & 1.96 & 1.08 & 0.93 \\
\hline
\end{tabular}

${ }^{2}$ Expressed relative to response to $\mathrm{Cs}-137$ photons.

${ }^{b}$ Expressed relative to response to Co-60 photons.

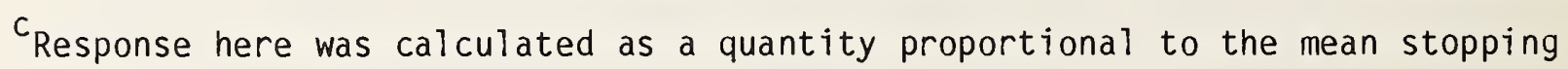
power of water: $\sum_{i} n_{i}\left(\bar{T}_{i}\right) s_{H_{2} 0}\left(\bar{T}_{i}\right) / \sum_{i} n_{i}\left(\bar{T}_{i}\right)$, where $n_{i}\left(\bar{T}_{i}\right)$ is the number of pulses in the ith pulse-height interval corresponding to an average electron energy $\bar{T}_{i}$, and $\mathrm{s}_{\mathrm{H}_{2} \mathrm{O}}\left(\overline{\mathrm{T}}_{i}\right)$ is the stopping power in water in this interval, restricted to electron energies $\geqslant 10 \mathrm{keV}$ [12]. The 10-keV cutoff corresponds to the lowest pulse-height measured with the silicon surface-barrier detector. 
radiation-protection instrumentation in the radiation fields of these sources; and (b) proposed guidelines for a measurement-assurance program that would establish and maintain traceability to NBS of the measurements performed by such secondary calibration laboratories. Recently, the proposed guidelines have been made available to the ad hoc committee of the Health Physics Society charged with studying the feasibility of establishing secondary calibration laboratories under the auspices of this Society. 


\section{REFERENCES}

[1] Mante1, Joseph. The beta ray spectrum and the average beta energy of several isotopes of interest in medicine and biology. Int. J. Appl. Radiat. Isotopes. 23: 407-413; 1972.

[2] Cross, William G.; Ing, Harry; Freedman, N. A short atlas of beta-ray spectra. Phys. Med. Biol. 28(11): 1251-1260; 1983.

[3] Bohm, Jurgen. Saturation corrections for plane-parallel ionization chambers. Phys. Med. Biol. 21(5): 754-759 1976.

[4] Bohm, Jurgen. The perturbation correction factor of ionization chambers in B-radiation fields. Phys. Med. Biol. 25(1): 65-75 1980.

[5] Bohm, Jưrgen. Standardization and calibration in beta dosimetry. Proceedings of the International Beta Dosimetry Symposium; 1983 February 15-18; Washington, D.C., U.S. Nuclear Regulatory Commission NUREG/CP-0050 73-97.

[6] Pruitt, John S. The effect of altitude on beta-ray source calibrations. Radiation Protection Dosimetry. 1985; in press.

[7] A handbook of radioactivity measurements procedures. National Council on Radiation Protection and Measurements. NCRP Report No. 58; 1978 November 1. $506 \mathrm{p}$.

[8] American National Standard for dosimetry - personnel dosimetry performance - criteria for testing. Am. Nat. Standards Institute ANSI N13.11-1983. 24 p.

[9] Reference beta radiations for calibrating dosimeters and doseratemeters and for determining their response as a function of beta radiation energy. International Organization for Standardization. ISO 6980; 1984 July. $8 p$.

[10] DOE laboratory accreditation proyram for personnel dosimetry systems. Part II: Standard for the performance testing of personnel dosimetry systems. Department of Energy; Draft. $24 \mathrm{p}$.

[11] The material covered in this section was presented by Christopher G. Soares at the Eighth Conference on the Application of Accelerators in Research and Industry; Denton, TX; 1984 November 12-14. It will be published as: Soares, Christopher G; Dick, Charles E.; Pruitt, John S.; Sparrow, Julian $H$. Development of monoenergetic electron beam sources for radiation instrument calibration. Nucl. Inst. Meth. Phys. Research; 1985 ; in press.

[12] Berger, Martin J.; Seltzer, Stephen M. Stopping powers and ranges of electrons and positrons (2nd ed.). Nat. Bur. Stand. (U.S.) NBSIR 822550-A; 1983 February. 169 p. 
Beta-Particle Source Cal ibration Procedure and Error Analysis

John S. Pruitt

Absorbed dose rates in water are determined from current measurements with an extrapolation ionization chamber and are calculated from the equation:

$$
\dot{D}=\frac{(W / e) \times S_{a}^{W} \times k_{S} \times k_{T} \times k_{D} \times k_{H} \times k_{A}}{\rho_{a} \times A} \times \frac{d i_{C}}{d s}
$$

where:

$(W / e)$ is the energy expended per unit ionization charge in air $S_{a}^{W}$ is the ratio of the average stopping power of water to that of air $k_{s}$ is the backscatter correction to make PMMA approximate water $k_{T}$ is a transmission correction to arbitrary depth in water $k_{D}$ is a correction for source decay $\mathrm{k}_{\mathrm{H}}$ is a correction for humidity variations

$k_{A}$ corrects the incident beam flux density to that of air at reference temperature and pressure

$\rho_{a}$ is the density of air at the reference temperature $\left(22^{\circ} \mathrm{C}\right)$ and pressure $(760 \mathrm{mH})$

$A$ is the area of the charge collecting el ectrode ( ${ } i_{c} / d s$ ) is the rate of change of corrected current with air gap spacing. 
Each measured current is corrected to a set of reference conditions by the equation:

$$
i_{C}=i f_{T} f_{S} f_{R}
$$

where:

$i$ is the measured current

$f_{T}$ corrects the air density inside the chamber to reference temperature and pressure

$f_{S}$ corrects for scatter and/or shielding from the chamber walls

$f_{R}$ corrects for ion recombination and diffusion inside the chamber.

Corrected currents are determined for five different air-gap settings $(s=0.5,1.0,1.5,2.0$, and $2.5 \mathrm{~mm})$. These are fitted to the straight 1 ine:

$$
i_{c}=c_{0}+c_{1} s
$$

and the coefficients $c_{0}$ and $c_{1}=\left(\mathrm{di}_{\mathrm{c}} / \mathrm{ds}\right)$ are determined by 1 east squares fit. Estimated systematic uncertainties plus statistical uncertainties measured for our own Buchler sources are 1 isted in the table. The systematic uncertainties are taken to be 67-percent estimates; therefore, they can be treated like standard deviations. The first four have been combined in quadrature to produce systematic uncertainty \#5. If systematic uncertainties \#5 through \#14 are combined in quadrature the total systematic uncertainty for the cal ibration becomes $1.3 \%$.

The statistical uncertainties are given as standard deviations calculated for the constant $c_{1}=\left(d i{ }_{c} / d s\right)$ from the 1 east-squares fit 


$$
\begin{gathered}
\sigma\left(c_{1}\right)=\sigma_{0} \sqrt{N / \Delta} \\
\Delta=N \Sigma s^{2}-(\Sigma s)^{2} \\
\sigma_{0}=\sqrt{\frac{\sum\left(C_{0}+C_{1} s-i_{C}\right)^{2}}{N-2}} .
\end{gathered}
$$

The degrees of freedom $(\mathrm{N}-2)$ for the calculations with the $147 \mathrm{Pm}, 204 \mathrm{Tl}$, and $90 \mathrm{Sr}+90 \mathrm{y}$ sources are 149,111 , and 39 respectively. 
Systematic and Statistical Uncertainties

\begin{tabular}{|c|c|c|c|}
\hline \multirow[b]{2}{*}{ Quantity } & \multirow[b]{2}{*}{ Symbol } & \multicolumn{2}{|c|}{ Uncertainty } \\
\hline & & Systematic & Statistical \\
\hline $\begin{array}{l}\text { 1. Measured current } \\
\text { 2. Interior air density correction } \\
\text { 3. Chamber wall correction } \\
\text { 4. Saturation correction } \\
\text { 5. Corrected current per unit gap } \\
\text { a. } 147 \mathrm{Pm} \text { source } \\
\text { b. } 204 \mathrm{~T} \text { source } \\
\text { c. } 90 \text { Sr+90y source } \\
\text { 6. Air ionization constant } \\
\text { 7. Stopping power ratio } \\
\text { 8. Backscatter correction } \\
\text { 9. Transmission correction } \\
\text { 10. Source decay correction } \\
\text { 11. Altitude correction } \\
\text { 12. Humidity correction } \\
\text { 13. Reference air density } \\
\text { 14. Collecting el ectrode area }\end{array}$ & $\begin{array}{c}i \\
f_{T} \\
f_{S} \\
f_{R} \\
\left(d i_{C} / d s\right)\end{array}$ & $\begin{array}{l}0.1 \% \\
0.1 \% \\
0.2 \% \\
0.4 \% \\
0.5 \% \\
0.5 \% \\
0.5 \% \\
0.4 \% \\
0.7 \% \\
0.7 \% \\
0.4 \% \\
0.05 \% \\
0.3 \% \\
0.1 \% \\
0.05 \% \\
0.1 \%\end{array}$ & $\begin{array}{l} \pm 0.4 \% \\
\pm 0.3 \% \\
\pm 0.1 \%\end{array}$ \\
\hline
\end{tabular}


Appendix 2

Proposed Guidelines for Establishing a Secondary Calibration Laboratory for Beta-Particle Source Standardization and Calibration of Beta-Particle Protection Instruments

Margarete Ehrlich

1. Purpose of Secondary Calibration Facility. To provide routine calibrations, traceable to the National Bureau of Standards (NBS), for U.S. Users of betaparticle survey and personnel dosimetry instrumentation; and to provide standardizations of beta-particle secondary-standard sources employed in radiation protection, by means of a comparison with reference-class ionization chambers calibrated at NBS.

\section{Organizational Structure and Staff}

2.1 The secondary beta-particle calibration facility in general may be a part of a larger organization carrying out radiation-instrument calibrations for other types of radiation.

2.2 The facility shall be under the full-time supervision of a radiation physicist with an advanced degree on at least the master's level in physics or in a health-physics-related subject, and at least five years of practical experience in radiation-protection dosimetry. The staff devoting its full time to radiation-instrument calibration should consist of at least one physicist with two or more years of experience in radiation measurement, and one technician.

2.3 The staff shall have ready access to the services of a machine shop, an electronic-instrument repair shop, a computer, and a secretary. 
3.1 The physical plant shall consist of at least one irradiation room (preferably there should be two), and suitable storage, setup and office space, all designed to meet applicable Federal, State, and local safety codes and regulations.

3.2 The physical plant shall be sufficiently shielded from extraneous radiation sources so that the radiation background due to such sources is restricted to a level comparable to natural background, at all times.

3.3 The plant shall be provided with an air-conditioning system adequate to furnish controllable conditions of ambient temperature and relative humidity throughout the plant.

3.4 The plant shall be provided with an adequate grounding system and should be free of undue vibration, shock, acoustic noise, debris and dust.

3.5 Each irradiation room shall be partitioned into an irradiation area and a control area that is completely shielded from the beta particles in the irradiation area but preferably permits a view of the irradiation setup. The size and shape of the irradiation rooms shall be such as to permit the betaparticle sources to be positioned in the irradiation areas so that the contribution to the dose at the point of instrument calibration arising from room scatter (including bremsstrahlung) is less than five percent.

\section{Beta-Particle Sources}

4.1 The laboratory shall be equipped with at least one BuchlerAmersham "Complete Beta-Particle Inactive Plant" and one set of four associated beta-particle sources (two ${ }^{90} \mathrm{Sr}+90 \mathrm{Y}$ sources, one ${ }^{147 \mathrm{Pm}}$ source, and one $204 T 1$ source), standardized at NBS.

4.2 There should be access to additional standardized betaparticle sources of the same and of a different type (different radionuclide, different geometry). 
5. Beta-Particle Measurement Equipment and Accessories. The Taboratory shal1 own at least the following equipment and accessories, dedicated to the use in beta-particle calibration work, with redundant equipment of dissimilar type to that in actual use:

5.1 Two plane-parallel thin-wall shallow ionization chambers of referenceclass* quality, for use (a) as transfer instruments in source-standardization activities and (b) to check on the constancy of the instrument-calibration setups. The chambers shall provide a useful operating range for all betaparticle sources at the prescribed distance (or distances) of operation. They shall have high stability and should be ruggedly constructed of material suitable to minimize change of response with age, temperature, humidity, and with exertion of moderate mechanical force.

5.2 Two electrometers to measure charge. They should be of the feedback type, with an open-loop gain of at least $10^{4}$ and an input offset current of less than $10^{-14} \mathrm{~A}$. The electrometer circuit shall be electrically guarded at the potential of the input-contact point. The charge-measurement system shall retain a charge with a decay time constant of at least $10^{6} \mathrm{~s}$.

5.3 Two capacitors for electrometer calibrations, with a stability of at least one part in $10^{3}$ per year and a time constant of at least $10^{5} \mathrm{~s}$.

5.4 Two 4 1/2-digit (or more) voltmeters. One should be capable of measuring at least 600 volts. Their accuracy shall be \pm 0.1 percent.

5.5 Plastic filters of appropriate size, and of a thickness range to permit the measurement of depth-dose curves.

*A reference-class instrument is an instrument exhibiting a performance and stability sufficient for it to be used for calibrating other instruments.

(IEC 62C-12) 
5.6 At least one calibration range, consisting of an instrument support (or supports) of adjustable, measurable, and reproducible height, traveling along a rail that, preferably, is rigidly connected to the source support and is equipped with a tape permitting the determination of source-to-support distance. The instrument support(s) shall be suited for positioning the survey meters to be calibrated, the personnel dosimeters to be irradiated, the planeparallel ionization chambers, and the sources to be standardized to a level of accuracy and reproducibility consistent with the respective calibration-accuracy goals.

5.7 It may be advisable to have a calibration range in each of two irradiation rooms, using one for instrument calibrations and irradiations and the other for simultaneous source standardizations.

5.8 A device for testing atmospheric communication of ionization chambers.

5.9 At least two high-quality barometers.

5.10 At least two high-quality thermometers, each with a resolution of $0.5{ }^{\circ} \mathrm{C}$ or better.

5.11 A device to measure relative humidity to meet the requirements of Section 6 .

5.12 At least one source of electric potential accurate to \pm 5 percent and with a short-term stability of \pm 0.1 percent, suitable for ionization-chamber polarity and charge measurements.

5.13 At least two thin-window survey instruments. 
6. Laboratory Operation

6.1 The physical plant shall be maintained to meet all applicable safety codes and regulations.

6.2 Ambient temperatures should be kept in the range of $22 \pm 3{ }^{\circ} \mathrm{C}$ and ambient relative humidities in the 15-to 65-percent range. The ambient conditions shall be sufficiently uniform throughout the physical plant to ensure adequate stabilization of both the laboratory's measurement equipment and the equipment submitted for calibration and/or other services.

6.3 All laboratory equipment shall be maintained in working order and shall be calibrated periodically in accordance with the following plan:

6.3.1 At least one of the laboratory's plane-parallel ionization chambers shall be calibrated by NBS over the full range of energies for which it is used. The calibration schedule should be established in accordance with NBS policy for this type of instrument.

6.3.2 At least one of the laboratory standard voltmeters and one of the capacitors used for charge measurements shall be calibrated at least biennially at another facility; these calibrations shall be documented as being directly traceable to NBS.

6.3.3 At least one barometer and one thermometer shall have a calibration documented as directly traceable to NBS.

6.4 The standardization of the beta-particle sources at the specified distance(s) and the delivery of prescribed values of absorbed dose to personnel dosimeters at these distances shall be in agreement with the National Standard to within \pm 3 percent at the 95 -percent confidence level. The calibration factors obtained for radiation-protection instruments shall agree with those obtained by NBS to within \pm 5 percent at the 95 -percent confidence level. 
6.5 Internal quality-assurance measures shall be designed to discover changes in equipment performance that would adversely affect the quality of the laboratory's operation. The laboratory's performance shall be tested by NBS according to a schedule developed in consultation with NBS, and corrective actions shall be taken promptly, if required, in order to maintain compliance with the accuracy requirements stated in 6.4 .

6.6 The laboratory shall have a written operations protocol that includes:

6.6.1 a statement of the scope of its work, including the types of beta-particle sources accepted for standardization, the type of radiationprotection instruments accepted for calibration or irradiation, and the range of dose-equivalent rates and source-to-detector distances over which these services are performed;

6.6.2 an inventory of all pieces of equipment used in the betaparticle calibration and standardization work, including model and serial numbers, where applicable;

6.6.3 an outline of equipment-maintenance and instrument-calibration policy;

6.6.4 the operational steps outlined in sufficient detail to permit a knowledgeable person new to the operation to carry out each step reproducibly to a precision consistent with the goals of the laboratory;

6.6.5 the accuracies of the calibrations and standardizations performed;

6.6.6 an outline of how records of the entire operation are accumulated and stored, and how the security of proprietary information is ensured;

6.6.7 the procedure for auditing measurement results and approving reports; 
6.6.8 an outline of internal and external quality-control procedures and schedules.

\section{Records}

7.1 A comprehensive and readily accessible record system shall be maintained. It shall include at least the following information:

7.1.1 a full history of all laboratory equipment and instrumentation, including dates of purchase, calibration and maintenance, certificates and operating instructions;

7.1.2 date of receipt of instrument or source, serial number, details of required tests, certificate and invoice (or other accounting) numbers, date of completion of work, of return shipment, and of test report;

7.1.3 actual measurement data for the standardization of sources, for the calibration of instruments, and for measurements associated with personneldosimeter irradiations;

\subsection{4 copies of all reports issued.}

7.2 All records shall be kept for a period of time sufficient to comply with all pertinent local, State, and Federal legal requirements.

\section{Test Reports}

8.1 The test reports shall consist basically of a statement giving:

8.1.1 for source standardizations, absorbed-dose rate at a specified source-to-detector distance at a specified depth in the material of interest;

8.1.2 for instrument calibrations, the correction or calibration factors for use of the instrument at a specified distance from a specified source: 
8.1.3 for personnel-dosimeter irradiations, the absorbed-dose to the material of interest administered to the dosimeters at a specified distance from the source.

8.2 The test report shall include further:

8.2.1 name and address of the calibration laboratory;

8.2.2 report date and number;

8.2.3 person or institution submitting the instrument or source;

8.2.4 type and serial number of item submitted;

8.2.5 pertinent parameters regarding geometry, ambient conditions, radiation fields, instrument settings and instrument orientation applying to the reported test results;

8.2.6 initials or signature of the person who performed the tests, and signature of the person responsible for the laboratory operations.

8.3 The test results shall not be disclosed to anyone other than the individual or institution submitting the item for test, except as designated in writing by the individual or institution, or as required by law. 
Proposed Guidelines for Establishing a Secondary Calibration Laboratory for Neutron-Protection Instruments

Robert B. Schwartz

1. Purpose of Secondary Calibration Facility. To provide routine calibrations, traceable to the National Bureau of Standards (NBS), for U.S. users of neutron survey and personnel dosimetry instrumentation.

2. Organizational Structure and Staff

2.1 The secondary neutron instrument calibration facility in general may be a part of a larger organization carrying out radiation-instrument calibrations for other types of radiation.

2.2 The facility shall be under the supervision of a radiation physicist with an advanced degree on at least the master's level in physics or in a health-physics-related subject, and at least five years of experience in radiation protection dosimetry or in neutron radiation measurements. His staff shall consist of at least one other physicist and one technician.

2.3 The staff shall have access to the services of a machine shop, an electronics shop, a computer, and a secretary.

3. Physical Facility

3.1 The physical plant shall consist of at least one irradiation room and suitable storage, setup, and office space, all designed to meet applicable Federal, state, and local safety codes and regulations.

3.2 The physical plant shall be sufficiently shielded from extraneous radiation sources so that the neutron background due to such sources is $\leqslant 0.1 \mathrm{mrem} / \mathrm{h}$. 
3.3 The plant shall be provided with an air-conditioning and heating system adequate to furnish controllable conditions of ambient temperature and relative humidity throughout the plant.

3.4 The plant should be free of undue vibration, shock, noise, debris and dust.

3.5 The irradiation room may be either "open" or "enclosed". An "open" room is one in which the walls and ceiling are generally of low mass, non-hydrogenous, material essentially transparent to neutrons. Radiation protection is provided by means of a sufficiently large exclusion area. An "enclosed" room is one in which the walls and ceiling are sufficiently massive (usually concrete) to provide adequate shielding for personnel in the vicinity. The enclosed room must be as large as possible to minimize the room-scattered neutron contribution, and, in any case, the inside linear dimensions must be $\geqslant 6 \mathrm{~m}$. The size of an open room may be considerably smaller. In either case, a control and data-taking area must be provided which is completely shielded from the irradiation area, but which permits viewing the irradiation setup either directly or by means of closed-circuit television.

\section{Neutron Sources and Moderator}

4.1 The laboratory shall be equipped with a 15-cm radius heavy water sphere, covered with cadmium, for producing moderated neutron spectra. The design of the sphere should be patterned after the NBS design, or be of similar construction which allows convenient insertion and removal of a californium source into the center of the sphere, and minimizes air spaces and extraneous material in the vicinity of the source.

4.2 The laboratory shall be set up so that calibrations may be performed with either "bare" (i.e., unmoderated) californium, or moderated californium. 
4.3 Since it is necessary to calibrate remmeters over a range of approximately 4 decades in dose equivalent rate, at least two californium sources of different strengths will be required. The stronger source should be sufficient to produce a dose equivalent rate of at least 3 $\mathrm{rem} / \mathrm{h}$, or 75 percent of the instrument's maximum scale reading, whichever is lower. For a bare source and spherical detector, the minimum source-detector center-to-center distance shall be greater than 3 sphere radii; for a cylindrical detector the minimum distance must be greater than 5 cylinder radii. For a 9-inch spherical remmeter, the minimum emission rate of the "strong" size should thus be $\sim 4 \times 10^{8}$ $n / s$.

The weaker source should be chosen to produce a field of $3 \mathrm{mrem} / \mathrm{h}$ or less at a distance such that the ratio of the instrument's response to the room-scattered neutrons to its response to the direct-source neutrons is less than 40 percent. For a bare californium source irradiating a nine-inch spherical remmeter in a cubical concrete room, the maximum emission rate, $Q$, of the weak source will be roughly

$$
Q \approx 1.5 \times 10^{5} \mathrm{a}^{2} \mathrm{n} / \mathrm{s}
$$

where $a$ is the length in meters of one of the sides of the cubical room.

The exact emission rates of the sources should be worked out in conjunction with NBS, taking account of room scatter, minimum source-todetector distance, allowance for source decay, and the differences between bare and moderated calibrations. All sources must be calibrated by NBS.

\section{Equipment and Accessories}

5.1 The laboratory shall own at least one of whatever types of remmeters it will be called upon to calibrate regularly. Specifically, this means the Eberline 9-inch remmeter, but may also include a commercial version of the Andersson-Braun remmeter. Where possible, the digital version of the instrument should be chosen, rather than analog. 
5.2 Closed-circuit television equipment, so that the instrument under test can be read from the control room.

5.3 A thermometer and a device for measuring relative humidity.

5.4 A calibration range consisting of a low mass instrument support stand of adjustable height traveling along rails. It would be highly preferable to have the instrument stand motor-driven, with remote control and remote read-out of its position.

5.5 A $40 \mathrm{~cm} \times 40 \mathrm{~cm} \times 15-\mathrm{cm}$ thick acrylic (polymethylmethacrylate) phantom.

\section{Laboratory Operation}

6.1 The physical plant shall be maintained to meet all applicable safety codes and regulations.

6.2 Ambient temperatures should be kept in the range of $22 \pm 3^{\circ} \mathrm{C}$ and ambient relative humidities in the 15- to 65-percent range. The ambient conditions shall be sufficiently uniform throughout the physical plant to ensure adequate stabilization of both the laboratory's measurement equipment and the equipment submitted for calibration and/or other services.

6.3 The 1aboratory shall measure the effects of room-scattered neutrons for the more commonly calibrated instruments. These will include, as a minimum, the 9 -inch spherical remmeter, the 3-inch Eberline sphere, and albedo dosimeters. Room scatter effects for other instruments may be obtained by calculation and extrapolation from other measurements, although it is preferable that they also be measured directly. NBS shall assist in the analysis of the room scatter data.

6.4 Corrections for air scatter and for departure from the $1 / r^{2} 1$ aw shal1 be provided by NBS. 
6.5 The laboratory remmeter (section 5.1 ) shall be carefully calibrated by measuring its response as a function of dose equivalent at at least several points per decade, for both the bare and moderated californium sources. The instrument's dead time should be carefuly measured, and it should be checked for any drift or warm-up problems. The laboratory should also determine the response of the remmeter to room-scattered neutrons, as required by 6.3 . The instrument should then also be calibrated by NBS, and the calibrations compared.

Once the instrument's behavior is well understood and it has been carefully calibrated, it becomes the laboratory's "standard remmeter". It is then periodically intercompared with other remmeters being calibrated. Note that calibrations are always done in terms of a dose equivalent rate calculated from the source emission rate (measured at NBS) and the distance, with allowances made for wall scatter and air scatter. Calibrations are not to be done by comparing with the laboratory standard remmeter. Rather, the periodic checking of the laboratory standard is part of the SSL'S own quality control, done by recalibrating the standard instrument at periodic intervals, along with other instruments requiring calibration. Each time this is done, the calibration factor for the laboratory instrument shall be recorded, and deviations from the expected value shall be investigated.

\section{Records}

7.1 A comprehensive and readily accessible record system shall be maintained. It shall include at least the following information:

7.1.1 a full history of all laboratory equipment and instrumentation, including dates of purchase, calibration and maintenance, certificates and operating instructions;

7.1.2 date of receipt of instrument or source, serial number, details of required tests, certificate and invoice (or other accounting) numbers, date of completion of work, of return shipment, and of test report; 
7.1.3 actual measurement data for the standardization of sources, for the calibration of instruments, and for measurements associated with personnel-dosimeter irradiations;

7.1.4 copies of all reports issued.

7.2 All records shall be kept for a period of time sufficient to comply with all pertinent Federal, state, and local legal requirements.

8. Test Reports

8.1 The test report shall include the following information:

- Name and address of calibration laboratory

- Report or calibration number

- Name and address of person or institution submitting the instrument to be tested

- Type and serial number of item submitted

- Date of irradiation

- Identification numbers of the californium sources used, together with their emission rates at the time of the irradiation, and whether used bare or moderated

- Average temperature and relative humidity during the irradiation

- Signature of person performing the irradiations, and of the person responsible for the laboratory operation

8.1.1 For remmeter calibrations, the report shall include the following information for each calibration point:
(a) Source number
(b) Source-to-detector center-to-center distance
(c) Calculated free field dose equivalent rate at remmeter
(d) Instrument reading
(e) Instrument reading corrected for scattering effects
(f) Calibration factor (i.e., (c)/(e) of 8.1.1)
(g) Estimated uncertainty in the calibration factor 
8.1.2 For dosimeter irradiations, the test report shall include the following information:
(a) Source number
(b) Source center-to-phantom front face distance
(c) Calculated free field dose equivalent rate at phantom front face
(d) Irradiation time
(e) Total free field dose equivalent (i.e., (c) $\times$ (d) of 8.1.2)
(f) Total dose equivalent corrected for room and air scatter- ing
(g) Estimated uncertainty in the total corrected dose equiva- lent

8.2 All test reports shall also include a brief narrative description of the physical arrangement for the irradiations, and a brief discussion of the uncertainties. The report shall also include, if appropriate, a discussion of any unusual behavior exhibited by the instrument under test.

8.3 The test results shall not be disclosed to anyone other than the individual or institution submitting the item for test, except as designated in writing by the individual or institution, or as required by 1 aw. 
Proposed Procedure for Carrying out Measurement-Assurance Studies for a Secondary Calibration Laboratory

Margarete Ehrlich

1. Purpose

The purpose of measurement-assurance studies is to demonstrate that instrument calibrations and source standardizations performed by a secondary calibration laboratory agree with national measurement standards, within the accuracy specified in the operating protocol of the secondary laboratory.

\section{Mechanism}

All measurement-assurance studies shall be carried out by the National Bureau of Standards (NBS) on a periodic basis, following a schedule agreed upon between NBS and the secondary calibration laboratory (SCL). The following tasks shall be included:

\subsection{Photons}

The SCL shall calibrate two NBS-calibrated reference-class ionization chambers in all the photon beams to be used in the calibration work. The results shall be evaluated by NBS.

\subsection{Beta Particles}

The SCL shall calibrate one or more NBS-calibrated parallel-plate ionization chambers with the sources and at the distances to be used in the calibration work. The results shall be evaluated by NBS.

\section{$2.3 \quad$ Neutrons}

2.3.1 For measurement-assurance studies related to the calibration of personnel dosimeters. (a) The SCL shall irradiate, on phantom, albedo TLDs provided by NBS or by another laboratory designated by NBS, at five distances 
from a bare and a moderated ${ }^{252} \mathrm{Cf}$ source. A total of 25 dosimeters shall be used at each source, five each at each of the five distances ranging from 0.3 to $2 \mathrm{~m}$. (b) If the albedo TLDs originate at a laboratory other than NBS, this laboratory shall simultaneously send another 10 of their dosimeters to NBS, for irradiation at the SCL calibration distance in the fields of the NBS bare and moderated ${ }^{252} \mathrm{Cf}$ sources. (c) After the return of all TLDs to their respective places of origin, they shall be read out, and the results transmitted to NBS for evaluation. If required, special procedures may be devised for SCL personnel-dosimeter calibration with other types of neutron sources.

\subsubsection{For measurement-assurance work related to the calibration of} neutron-survey meters (remmeters). The SCL shall calibrate an NBS-calibrated remmeter in terms of dose-equivalent rate in the radiation field of its bare and moderated ${ }^{252} \mathrm{Cf}$ sources. The results shall be evaluated by NBS. If required, special procedures may be devised for SCL survey-instrument calibration with other types of neutron sources. 


$$
\text { . }
$$




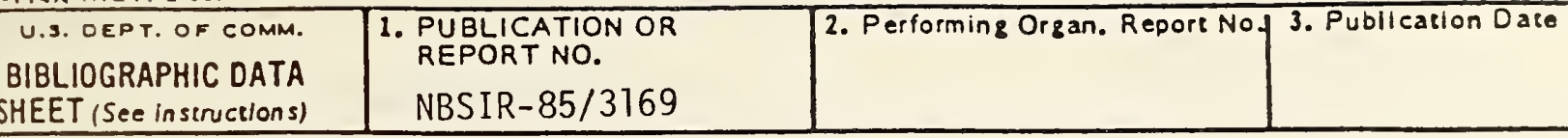

4. TITLE ANO SUBTITLE

STANDARD BETA-PARTICLE AND MONOENERGETIC ELECTRON SOURCES FOR THE CALIBRATION OF BETA-RADIATION PROTECTION INSTRUMENTATION

5. AUTHOR(S)

Ehrlich, M., Pruitt, j.S., Suares, C.G.

6. PERFORMING ORGANIZATION (If joint or other th on NBS, see instructions)

MATIONAL BUREAU OF STANDARDS

DEPARTMENT OF COMMERCE

WASHINGTON, D.C. 20234

7. ConeracuGrant No.

Interagency Agreement No. $82-009$

8. Type of Repore \& Perlod Covered Final, Sept '82-Dec ' 84

9. SPONSORING ORGANIZATION NAME AND COMPLETE ADDRESS (Sireet, CItY, Stote, ZIP)

US Nuclear Regulatory Commission

Washington, D.C. 20555, jointly with NBS

10. SUPPLEMENTARY NOTES

Document describes a computer program; SF-185, FIPS Software Summary, is attached.

11. ABSTRACT (A 200-word or less foetuol summory of most slgnificont informotion. If document includes a slgnificon blbllogrophy or literotura survey, mention it hero)

In a project funded jointly by the National Bureau of Standards (NBS) and the Nuclear Regulatory Commission (NRC), NBS has developed a calibration facility for beta-particle instruments and sources used in radiation-protection dosimetry." "The facility consists of beta-particle and nearly monoenergetic electron beams characterized in terms of absorbed-dose rates to plastic and in terms of beta-particle spectra A second phase of the project was concerned with establishing secondary calibration laboratories for radiation-protection instruments.

This final report includes a detailed discussion of (1) the determination of absorbed =dose rates : to plastfc for each beta-particle and nearly monoenergetic electron beam, dose-rate dependence on altitude above sea level, and an estimate of the overal uncertainties in dose-rate measurements; (2) beta-particle and nearly monoenergetic electron spectra and their dependence on source configuration; and (3) degree of achievable uniformity of beam cross sections. Included also is a review of the results of a first attempt to predict. Instrument response to realistic beta-particle environments from their response to monoenergetic electrons and knowledge of the approximate beta-particle spectra. Attached to the report are proposed guidelines for establishing secondary calibration laboratories for radiation-protection. instruments.

12. KEY WOROS (51x to twelve ontrles; alphabetlcol order: copitallze only proper names; and soparate key words by semicolon s) Apsorbed:dose::to:plastdc; beta-particle sources; electrons (nearly monoenergetic); energy spectra; guidelines for secondary calibration labs; instrument calibration; prometheum147; radiation protection; strontium-90 + yttrium-90; thal11um-204.

13. AVAILABILITY

D Unilimited

$\square$ For Officlal Distribution. Do Not Release to NTIS

Order From Superintendent of Documents, U.S. Government Printing Offico, Washincton, D.C. 20402.

14. NO. OF

PRINTED PAGES 72 


UNITED STATES

NUCLEAR REGULATORY COMMISSION

WASHINGTON, D.C. 20555

OFFICIAL BUSINESS

PENALTY FOR PRIVATE USE, $\$ 300$
FOURTH CLASS MAIL

POSTAGE G FEES PAID USNRC

WASH D C

PERMIT NO $G 67$ 